Discussion Paper No. 07-038

Developing Supra-European Emissions Trading Schemes:

An Efficiency and International Trade Analysis

Victoria Alexeeva-Talebi and Niels Anger

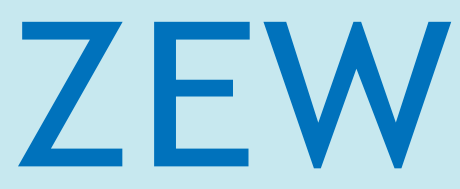

Zentrum für Europäische Wirtschaftsforschung $\mathrm{GmbH}$

Centre for European

Economic Research 
Discussion Paper No. 07-038

\title{
Developing Supra-European Emissions Trading Schemes: An Efficiency and International Trade Analysis
}

\author{
Victoria Alexeeva-Talebi and Niels Anger
}

Download this ZEW Discussion Paper from our ftp server:

ftp://ftp.zew.de/pub/zew-docs/dp/dp07038.pdf

Die Discussion Papers dienen einer möglichst schnellen Verbreitung von neueren Forschungsarbeiten des ZEW. Die Beiträge liegen in alleiniger Verantwortung der Autoren und stellen nicht notwendigerweise die Meinung des ZEW dar.

Discussion Papers are intended to make results of ZEW research promptly available to other economists in order to encourage discussion and suggestions for revisions. The authors are solely responsible for the contents which do not necessarily represent the opinion of the ZEW. 


\section{Non-technical summary}

The most prominent instrument of current European climate policy is the EU Emissions Trading Scheme (ETS) which is operating at the installation level in a "warm-up" phase since 2005. More recently, the EU has proposed to strengthen the European ETS by linking the scheme to emerging trading systems beyond Europe in order to more cost-efficiently achieve its climate policy objectives. At the same time, countries like Canada, Japan or Australia are considering the set up of domestic ETS with the intention of linking up to the European scheme. The EU ETS may thus form the nucleus for a gradually expanding company-based emissions trading system at the global level. Given the coexistent EU priorities with respect to competitiveness of European industries and international emissions regulation at the company level, this paper assesses the efficiency and competitiveness implications of linking the EU ETS to emerging trading schemes outside Europe.

Employing both economic theory and a large-scale computable general equilibrium model of the global economy, in this paper we (i) analytically derive the efficiency aspects of integrating emissions trading schemes from a partial market perspective, (ii) numerically analyze the aggregate welfare impacts of linking the EU ETS and (iii) explicitly assess the economy-wide and sectoral competitiveness effects of developing supra-European emissions trading schemes in the year 2020.

While a stylized partial-market analysis suggests that the integration of trading systems is always beneficial in efficiency terms, our applied general equilibrium approach shows that the aggregate welfare impacts of linking the EU ETS are rather limited. We further find that the trade-based competitiveness effects of linking the European ETS crucially depend on the linked trading system: Although EU economy-wide competitiveness varies only moderately across linking scenarios, the sectoral decomposition of these aggregate effects shows that European industries are much more sensitive to the linking constellation. Regarding the international trade impacts for non-EU countries, we find that the linking candidates have very heterogeneous incentives to join the European trading system, which range from pronounced competitiveness improvements for Canada to substantial competitiveness losses for Japan. Our sensitivity analysis assuming a stricter allowance allocation within regional trading systems suggests, however, that a more efficient design of domestic ETS can boost the overall prospects for establishing supra-European emissions trading schemes. 


\title{
Developing Supra-European Emissions Trading Schemes:
}

\section{An Efficiency and International Trade Analysis}

\author{
Victoria Alexeeva-Talebi and Niels Anger* \\ Centre for European Economic Research (ZEW), Mannheim, Germany \\ E-mails: alexeeva-talebi@zew.de, anger@zew.de
}

\begin{abstract}
Given the coexistent EU priorities concerning the competitiveness of European industries and international emissions regulation at the company level, this paper assesses the efficiency and competitiveness implications of linking the EU Emissions Trading Scheme (ETS) to emerging trading schemes outside Europe. Currently, countries like Canada, Japan or Australia are contemplating the set up of domestic ETS with the intention of linking up to the European scheme. While a stylized partial-market analysis suggests that the integration of trading systems is always beneficial in efficiency terms, our applied general equilibrium approach shows that the aggregate welfare impacts of linking the EU ETS are rather limited. We further find that the trade-based competitiveness effects of linking the European ETS crucially depend on the linked trading system: Although EU economy-wide competitiveness varies only moderately across linking scenarios, the sectoral decomposition of these aggregate effects shows that European industries are much more sensitive to the linking constellation. Similarly, the incentives for non-EU regions to join the European system display considerable heterogeneity. A stricter allowance allocation within domestic ETS can, however, substantially improve the overall prospects for establishing supra-European emissions trading schemes.
\end{abstract}

JEL Classification: D58, H21, H22, Q48

Keywords: Emissions Trading, EU ETS, Linking, Competitiveness, CGE model

Acknowledgements: The authors are grateful to Christoph Böhringer and Sabine Jokisch for valuable scientific advice. Funding by the European Commission under the framework contract B2/ENTR/05/091-FC is gratefully acknowledged.

\footnotetext{
* Corresponding author. Centre for European Economic Research (ZEW), P.O. Box 103443, 68034 Mannheim, Germany. Phone: +49 6211235 206. Fax: +49 6211235 226. E-mail: anger@zew.de
} 


\section{$1 \quad$ Introduction}

In March 2000, the European Council agreed at the Lisbon summit to make the European Union (EU) the most competitive economy of the world (EU, 2000). At the same time, the EU pursues ambitious climate policies in order to fulfil its emissions reduction targets under the Kyoto Protocol and to limit global climate change to two degrees Celsius in the long run (UNFCCC, 1997; EU, 2007a).

The most prominent instrument of current European climate policy is the EU Emissions Trading Scheme (ETS) which is operating at the installation level in a "warm-up" phase since 2005 (EU, 2003). Thereby, the EU has established a flexible climate policy instrument at the company level independently of the Kyoto Protocol (facilitating both international emissions trading between Annex B governments and project-based emissions reductions in developing countries via the Clean Development Mechanism, CDM). More recently, the EU has proposed to strengthen the European ETS by linking the scheme to emerging trading systems beyond Europe in order to more cost-efficiently achieve its climate policy objectives (EU, 2007a). The EU ETS may thus form the nucleus for a gradually expanding company-based emissions trading system at the global level. Reflecting the coexistent EU priorities concerning the competitiveness of European industries and international emissions regulation at the company level, this paper presents an efficiency and international trade analysis of future supraEuropean emissions trading schemes.

At present, several non-EU countries are contemplating the set up of domestic ETS at the national and regional level with the intention of linking up to the European scheme. In the short run, the already mature emissions trading schemes of Norway and Switzerland - which are designed similarly to the EU ETS - can be expected to be linked to the European system (Sterk, 2005) until 2010. In the mid-term perspective up to 2020, several parties having ratified the Kyoto Protocol - such as Canada, Japan and the Russian Federation - may also have incentives to join the EU ETS: Canada is already promoting the Large Final Emitter System to cover energy-intensive companies accounting for almost 50 percent of total Canadian greenhouse gas emissions (CEPA Environmental Registry, 2005). Japan has started the Pilot Project of a Domestic Emissions Trading Scheme on a voluntary basis, with circa 30 private companies participating in the program (Japanese Ministry of the Environment, 2004). Moreover, initial exploratory discussions on the potential linkage of trading schemes have already been held between the EU, Canada and Japan (EU, 2005; EU-Japan Centre for Industrial Cooperation, 2006). Also Russia may have incentives to develop a domestic 
emissions trading system in order to be linked to the European scheme and to exploit a larger market for the sale of excess emissions permits, so-called "Hot Air". Finally, linking the EU ETS to emerging schemes in Australia and the United States - which have so far not ratified the Kyoto-Protocol - could be considered as a first step in integrating both countries into an international climate policy regime. Indeed, Australia and United States are already promoting domestic emissions trading schemes: In the U.S., the Regional Greenhouse Gas Initiative being pushed by nine Northeast and Mid-Atlantic states - aims at establishing a regional trading system (RGGI, 2006). In Australia, the New South Wales Greenhouse Gas Abatement Scheme is already operating at the state level (New South Wales Government, 2006) and most recently, Australian state premiers have released initial proposals for a national cap and trade system starting in 2010 (Point Carbon, 2006). To sum up, there are strong signals for emissions trading schemes to be established in non-EU countries and to be potentially linked to the European scheme by 2020 .

Previous quantitative economic analyses have focused on efficiency aspects (see e.g. Böhringer et al., 2005) and competitiveness implications of the current European trading scheme (Kemfert et al., 2005; Klepper and Peterson, 2004; Peterson 2006a) in applied partial and general equilibrium frameworks. However, only Peterson (2006b) addresses the competitiveness implications of EU emissions regulation explicitly by employing a tradebased competitiveness indicator. Regarding the linkage of the European ETS to emerging schemes outside Europe, a first economic impact assessment is presented by Anger (2006) within a partial equilibrium modelling framework. Further contributions examine economic and institutional aspects of linking the EU ETS internationally in a qualitative manner only (Kruger et al., 2007; Sterk et al, 2006; Blyth and Bosi, 2004). Against this background, the contribution of this paper is threefold: Employing both economic theory and a large-scale computable general equilibrium model of the global economy, we (i) analytically derive the efficiency aspects of integrating emissions trading schemes from a partial market perspective, (ii) numerically analyze the aggregate welfare impacts of linking the EU ETS and (iii) explicitly assess the economy-wide and sectoral competitiveness effects of developing supraEuropean emissions trading schemes in the year 2020.

This article is structured as follows: Section 2 lays out the theoretical background of our analysis. In section 3, we present the numerical framework underlying our quantitative impact assessment. Section 4 introduces policy scenarios of linking the EU ETS internationally. Section 5 summarizes our quantitative simulation results. In section 6 , we conclude. 


\section{Theoretical background}

In this section, we present a simple analytical model of the emissions market in order to lay out the theoretical background for our numerical analysis of linking the European ETS. For this purpose, we first analyze the general efficiency aspects of international emissions trading and subsequently assess the emissions market implications of linking alternative trading systems.

Following the stylized framework of Anger (2006), $R$ regions are assumed $(r=1, \ldots, R)$ to commit to individual emissions targets (e.g. targets under the Kyoto Protocol), yielding an absolute emissions budget $\bar{E}_{r}$ for each region. Abatement costs of those sectors covered by a domestic emissions trading scheme (in the following referred to as ETS sectors) and the remaining non-covered sectors (in the following referred to as NETS sectors) in each region are denoted by $A C_{r}^{E T S}(e)$ and $A C_{r}^{N E T S}(e)$, respectively. Abatement cost functions are decreasing, convex and differentiable in emissions $e$. Total abatement costs $A C_{r}\left(E_{r}\right)$ are the sum of the sectoral costs $A C_{r}^{E T S}\left(e_{r}^{E T S}\right)$ and $A C_{r}^{N E T S}\left(e_{r}^{N E T S}\right)$.

For all regions - with binding emissions targets (such as Annex B parties of the Kyoto Protocol) and without any commitments (such as CDM host countries) - cost minimization and profit maximization with respect to $e_{r}^{E T S}$ and $e_{r}^{N E T S}$ yields the following first-order condition:

$$
\sigma=-\frac{\partial A C_{r}^{E T S}}{\partial e_{r}^{E T S}}=-\frac{\partial A C_{r}^{N E T S}}{\partial e_{r}^{N E T S}}=-\frac{\partial A C_{r}}{\partial\left(e_{r}^{E T S}+e_{r}^{N E T S}\right)}
$$

For each region and sector, this cost-efficient solution implies that marginal abatement costs equal the permit price $\sigma$ and are thus equalized across all emissions sources. Optimal emissions can then be derived as $E_{r}^{*}, e_{r}^{E T S^{*}}, e_{r}^{N E T S^{*}}$, where $E_{r}^{*}=e_{r}^{E T S^{*}}+e_{r}^{N E T S^{*}}$. The difference between the total emissions budget $\bar{E}_{r}$ and aggregate optimal emissions $E_{r}^{*}$ yields the optimal total trade volume in emissions permits.

\subsection{An international emissions trading scheme}

We consider an international emissions trading scheme consisting of two regions, 1 and 2. Interregional trading of emissions permits is feasible only for a segment of each economy, i.e. 
only for the ETS sectors covered by the trading system. ${ }^{1}$ We denote $\overline{e_{r}^{E T S}}$ the regional emissions target for ETS sectors, i.e. an assigned emissions cap or the number of allocated permits. Figure 1 illustrates the efficiency implications from trading emissions - in the absence of the CDM - in terms of compliance costs for the fulfillment of the regional emissions targets. The figure presents the corresponding economic impacts for the ETS sectors of the two regions that have (for simplicity linear) marginal abatement costs $\operatorname{MAC}_{1}^{E T S}\left(e_{1}^{E T S}\right)$ and $M A C_{2}^{E T S}\left(e_{2}^{E T S}\right)$ depending on regional emissions levels. We assume higher marginal abatement costs for region 1 than for region 2, equal maximum emissions for the two regions and equal regional emissions targets for the covered ETS sectors, amounting to 50 percent of their maximum emissions.

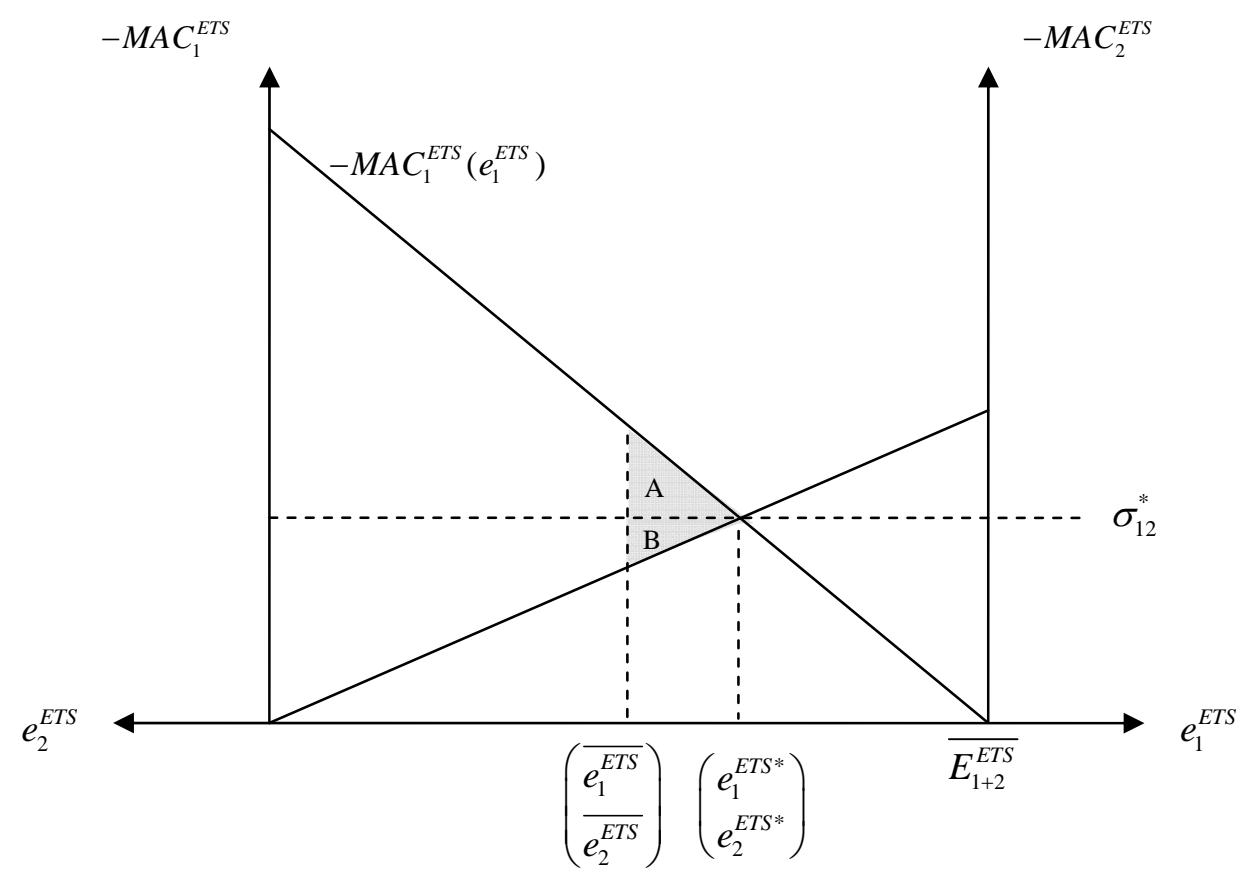

Figure 1: Sectoral efficiency gains in an international emissions trading scheme

According to Figure 1, the initial regional allocation of emissions permits $\left(\overline{e_{1}^{E T S}}, \overline{e_{2}^{E T S}}\right)$ to the covered ETS sectors, corresponding to a total emissions ceiling of $\overline{E_{1+2}^{E T S}}$, implies economically inefficient regional emissions levels as the associated marginal abatement costs differ between

\footnotetext{
${ }^{1}$ Anger (2006) shows that such a sectoral restriction of international emissions trading coupled with a generous allocation of emissions permits can cause large inefficiencies.
} 
the two regions. By means of international emissions trading, the high-cost (low-cost) region 1 (2) imports (exports) emissions permits from (to) the other region, thus increasing (reducing) its emissions. The resulting international permit price $\sigma_{12}^{*}$ equalizes marginal abatement costs and yields the optimal emissions levels $\left(e_{1}^{E T S^{*}}, e_{2}^{E T S^{*}}\right)$. As a consequence, international trading activities generate efficiency gains both for region 1 - due to avoided abatement costs exceeding permit import costs (equal to area A) - and for region 2 - due to larger permit export revenues than associated abatement costs (equal to area B).

\subsection{Linking of alternative trading schemes}

We extend the bilateral perspective of Figure 1 by introducing an additional region that may be linked to the joint trading scheme of region 1 and 2 (both regions have the same characteristics as in Figure 1). Hereby, we distinguish the following two cases: linking to a high-cost region (3) with marginal abatement costs $M A C_{3}^{E T S}\left(e_{3}^{E T S}\right)$ and linking to a low-cost region (4) with marginal abatement costs $M_{A} C_{4}^{E T S}\left(e_{4}^{E T S}\right)$. Both regions are assumed to exhibit the same maximum amount of emissions as the joint scheme of region 1 and 2. Analogously to the existing trading system, the linking candidates restrict emissions trading to their ETS sectors which face identical emissions targets $\overline{e_{3}^{E T S}}$ and $\overline{e_{4}^{E T S}}$ amounting to 50 percent of their maximum emissions. These ceilings correspond to the overall emissions target of the existing trading scheme $\overline{E_{1+2}^{E T S}}$ which features an aggregate marginal abatement cost function $\operatorname{MAC}_{1+2}^{E T S}\left(E_{1+2}^{E T S}\right)$. Figure 2 illustrates the efficiency aspects for ETS sectors of linking an additional region to the existing trading scheme of region 1 and 2. 


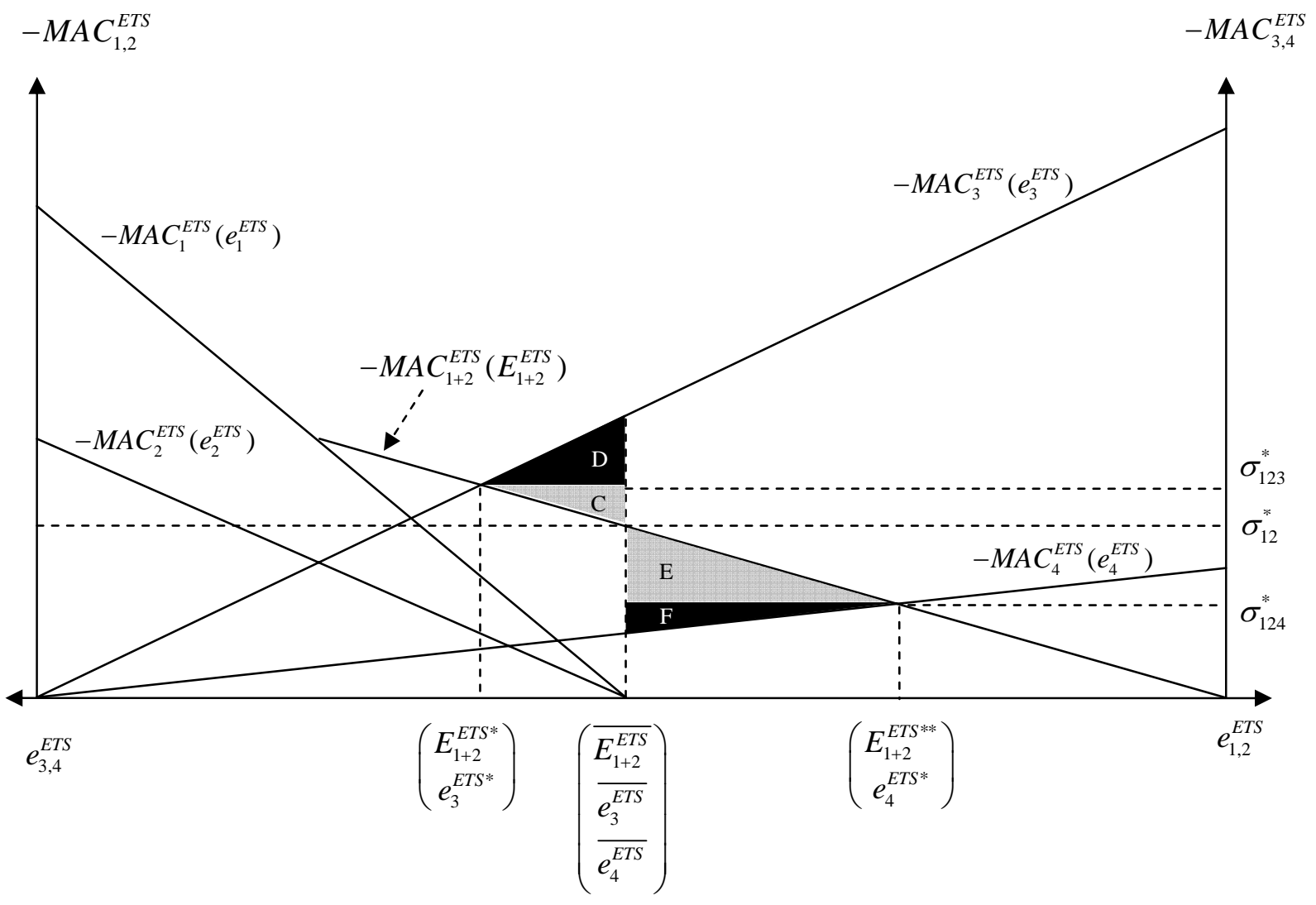

Figure 2: Additional efficiency gains from linking emissions trading schemes

In the case of linking the high-cost region 3 to the existing trading scheme, we observe that the initial allocation of emissions permits $\overline{E_{1+2}^{E T S}}$ and $\overline{e_{3}^{E T S}}$ to the covered ETS sectors again implies economically inefficient regional emissions levels. However, by means of international emissions trading the higher-cost region 3 may import permits from the lowercost existing scheme, yielding an increased international permit price of $\sigma_{123}^{*}$ as compared to $\sigma_{12}^{*}$ and optimal emissions levels $\left(E_{1+2}^{E T S^{*}}, e_{3}^{E T S^{*}}\right)$ with equalized marginal abatement costs. Compared to the initial allocation, in the new equilibrium region 3 increases its emissions while the existing scheme reduces pollution by the same amount. Thus, emissions trading activities induce efficiency gains for both the existing scheme (equal to area $\mathrm{C}$ ) and region 3 (equal to area D).

In contrast, linking to low-cost region 4 (initial permit allocation $\overline{e_{4}^{E T S}}$ ) implies that this region will export emissions permits to the higher-cost joint scheme of regions 1 and 2 . These trading activities yield a decreased international permit price of $\sigma_{124}^{*}$ and optimal emissions levels $\left(E_{1+2}^{E T S * *}, e_{4}^{E T S^{*}}\right)$ with reduced emissions of region 4 and similarly increased pollution of 
the joint scheme. This linking strategy generates efficiency gains both for the existing scheme (equal to area E) and region 4 (equal to area F). Thus, for the existing trading scheme linking to a high-cost or low-cost region implies positive incentives of a different magnitude illustrated by the two areas $\mathrm{C}$ and $\mathrm{E}$. In our case, the option to link to a low-cost candidate appears to be more preferable for the joint scheme, as the prospects of avoiding abatement costs by permit imports dominate the potential net benefits from exporting permits. Clearly, these incentives vary with the marginal abatement costs of the existing scheme and the respective linking candidates.

Our stylized partial market analysis suggests that - independently of the cost characteristics of a region to be linked with an existing scheme - the integration of trading systems yields economic efficiency gains for all participating regions. The reason is an increased whereflexibility of regional emissions abatement through an international linkage. Our stylized theoretical framework deliberately abstracts from real-world conditions regarding the regional heterogeneity of emissions levels, permit allocation and marginal abatement costs. In the next section we therefore present a numerical economic assessment of linking emissions trading schemes based on empirical data. Our applied general equilibrium model framework further enables us to analyze the associated indirect economic impacts that surpass the emissions market, affecting macroeconomic variables such as domestic production and international trade flows.

\section{$3 \quad$ Numerical framework}

In the following, we present the quantitative framework of our analysis. We first introduce our modeling approach and will then briefly discuss prerequisites and inputs for our policy assessment.

\subsection{Modelling approach}

In order to quantify the macroeconomic impacts of linking the EU ETS to emerging trading schemes outside Europe, it is crucial to account for complexities such as detailed production structures and market interactions. Computable general equilibrium (CGE) models have become the standard tool for applied economy-wide analysis of policy measures (for surveys on applications to environmental policies see Conrad 1999, 2001). The main virtue of the CGE approach is its comprehensive representation of price-dependent market interactions based on rigorous microeconomic theory. The simultaneous explanation of the origin and 
spending of agents' incomes makes it possible to address both economy-wide efficiency and distributional impacts of policy interference.

For our numerical analysis, we build on the PACE model (Policy Assessment based on Computable Equilibrium), a large-scale CGE model of international energy use and global trade (Böhringer and Vogt, 2003). In order to conduct an international trade analysis and assess the corresponding competitiveness effects of linking the EU Emissions Trading Scheme, we adapt the core PACE model by explicitly modelling export flows and prices.

The model reflects the key features of the European ETS and emerging non-EU trading schemes from a single country perspective: EU Member States and countries with domestic ETS outside Europe (linking candidates) are committed to specific carbon emissions constraints $\overline{\mathrm{CO} 2}$ which are agreed upon (e.g. under the Kyoto Protocol). Each of these countries must specify a cap $\bar{E}$ and the allocation rule for free emissions allowances to energy-intensive installations in six downstream sectors that are eligible for international emissions trading (electricity, oil refineries, iron and steel, non-ferrous metals, mineral industries and paper and pulp production). Assuming that the EU and non-EU emissions trading systems cover only energy-intensive industries implies that complementary domestic abatement policies are necessary for the non-covered sectors in order to comply with the remaining national emissions budget $(\overline{C O 2}-\bar{E})$.

Figure 3 provides a diagrammatic structure of the generic open-economy model. A representative agent $R A_{r}$ in each region $r$ is endowed with three primary factors: labour $\bar{L}_{r}$, capital $\bar{K}_{r}$, and fossil-fuel resources $\bar{Q}_{f f, r}$ (used for fossil fuel production). The representative agent maximizes utility from consumption of a composite good $C_{r}$ which combines demands for energy and non-energy commodities at a constant-elasticity-of-substitution (CES). Production $Y_{\text {ir }}$ of commodities $i$ in region $r$ is captured by nested separable CES functions that describe the price-dependent use of capital, labour, energy and material in production. Carbon emissions are linked in fixed proportions to the emissions-relevant use of fossil fuels through carbon coefficients which are differentiated by the specific carbon content of fuels. Carbon abatement, thus, can take place by fuel switching or energy savings in production and final consumption. 


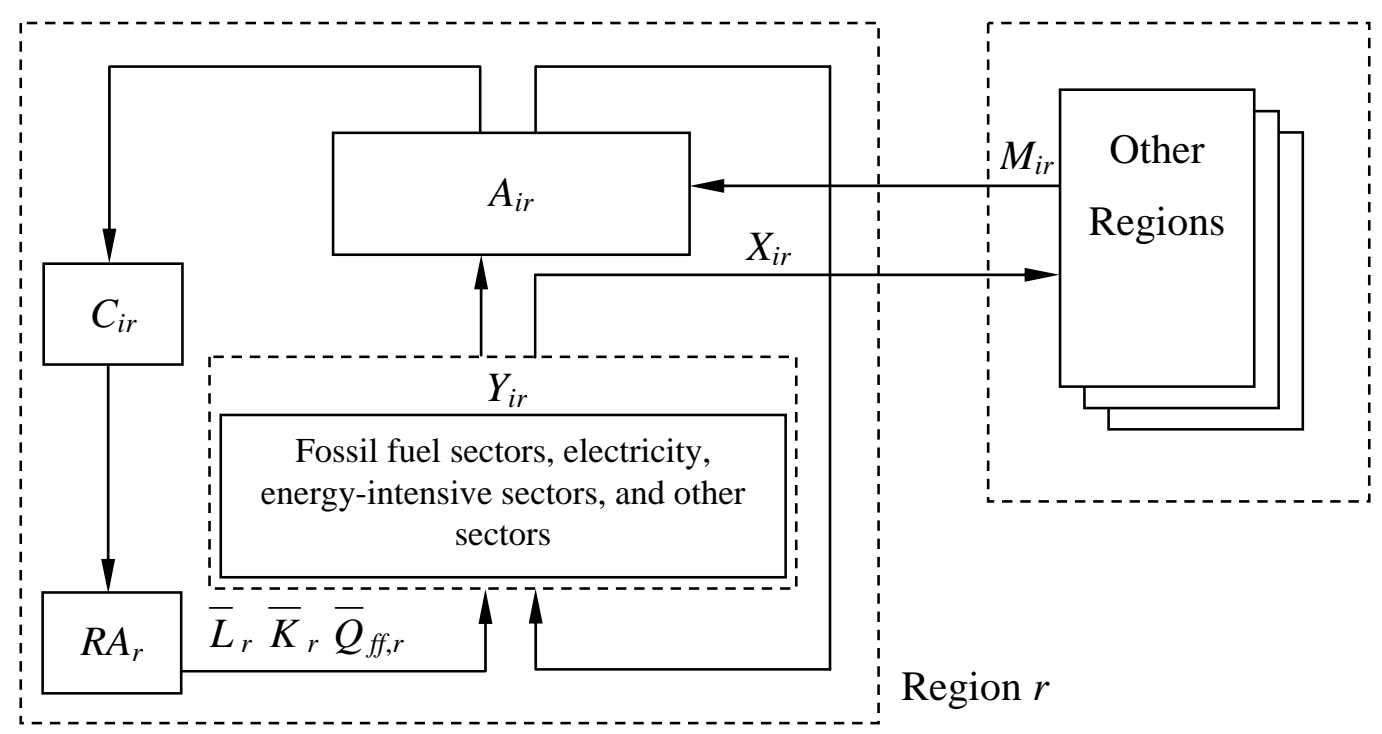

Figure 3: Diagrammatic overview of the model structure

The modelling of international trade is based on the Armington approach of product heterogeneity (Armington, 1969), so that domestic and foreign goods of the same variety are distinguished by their origin. All goods used on the domestic market in intermediate and final demand correspond to a CES composite $A_{i r}$ that combines the domestically produced variety $Y_{i r}$ and imports $M_{i r}$ of the same variety from other regions. Domestic production $Y_{i r}$ either enters the formation of the Armington good $A_{i r}$ or is exported $\left(X_{i r}\right)$ to other regions. Trade with other regions is represented by a set of horizontal export demand and import supply functions at exogenous world import and export prices. A balance of payment constraint, which is warranted through flexible exchange rates, incorporates the benchmark trade deficit or surplus.

The model is based on consistent accounts of national production and consumption, trade and energy flows for 2001 as provided by the GTAP 6 database (Dimaranan and McDougall, 2006). A detailed description of our benchmark data sources can be found in Appendix 8.1. The corresponding model regions and sectors of our analysis are presented in Appendix 8.2.

\subsection{Prerequisites for the quantitative analysis}

In this section, we present the set of relevant inputs for our numerical analysis. We include data on emissions reduction targets, allocation of emissions allowances to the sectors covered by emissions trading schemes, CDM transaction costs and investment risk indicators. 


\section{Emissions reduction targets and regional allowance allocation}

In order to analyze future climate policy strategies we have to assume emissions reduction commitments of the participating regions in the year 2020: Motivated by the ambitious future European climate policy goals, the EU (having committed to an EU-wide reduction of 8 percent under the Kyoto Protocol) is assumed to commit to a 20 percent reduction target vs. 1990 levels in 2020 (EU, 2007b). To this aim the heterogeneous regional Kyoto targets for EU Member States (as manifested by the EU Burden Sharing Agreement) are decreased by 13 percent in 2020. Given the assumed leadership role of European climate policy, those non-EU linking candidates having ratified the Kyoto Protocol (Canada, Japan and Russia) are assumed to tighten their Kyoto target by only 5 percent under a future climate policy agreement. Finally, the two non-ratifiers Australia and the United States commit to conservative targets that lie 32 percent and 17 percent above their respective (non-binding) Kyoto target, thereby facing comparable effective reduction requirements in 2020. The resulting commitments for 2020 are summarized in Table 2 of Appendix 8.1.

A further central input for our policy assessment is the allocation of emissions allowances for EU Member States and linking candidates which specifies an overall cap on emissions for those installations covered by the respective trading schemes. Here, we assume that the EU continues its predominant grandfathering method (i.e. a free allocation of allowances) to the covered installations in 2020. Numerically, emissions allocation can be described by so-called allocation factors, i.e. the fraction of baseline emissions that are freely allocated as allowances. In order to derive allocation factors for EU Member States in 2020 we rely on empirical allocation data for the second trading period of the EU ETS (2008 to 2012) - as published in the National Allocation Plan of each Member State - and on recent emissions projections for 2010 (EU, 2007c). Thereby, we conservatively assume that the relative allocation does not change between the second trading period and a future trading period in $2020 .^{2}$ Due to lacking information for Finland, Sweden, Bulgaria and Romania we assume a neutral allocation factor equal to one for these countries.

Regarding the emissions allocation for the non-EU regions Japan and Canada in 2020, we start from a neutral allocation factor equal to one in 2010 which is then downscaled by 10 percent, yielding an allocation factor of 0.90 in 2020. For Russia we assume an allocation factor equal to one in 2020, implying no allocation of excess permits to installations covered

\footnotetext{
${ }^{2}$ We relax this assumption by presenting a sensitivity analysis of the allowance allocation in section 5.4.
} 
by a Russian ETS. ${ }^{3}$ Finally, for the non-ratifiers United States and Australia, we downscale a neutral allocation factor of one in 2010 by 5 percent, resulting in an allocation factor of 0.95 in 2020. Thus, all allocation factors for linking candidates in 2020 lay above the (nonweighted) average allocation factor of the European Union (0.865), indicating a less strict emissions allocation to the covered sectors as compared to the European Union. Table 5 in Appendix 8.3 presents the resulting allocation factors for the EU and all linking candidates.

\section{CDM transaction costs and investment risk}

While the CDM serves as a flexible mechanism that enables industrialized countries to import low-cost emissions reductions in order to achieve their Kyoto targets, the potential economic benefits of the CDM may be substantially reduced by transaction costs associated with abatement projects in developing countries. Such transaction costs may arise from a variety of activities associated with market exchange, e.g. search and information acquisition, bargaining over prices, as well as negotiation, monitoring and enforcement of contracts. In our quantitative model framework, constant transaction costs are represented by an absolute premium on the marginal abatement costs of CDM host countries, amounting to $1 \mathrm{US} \$ / \mathrm{tCO}_{2}{ }^{4}$ Transaction costs, thereby, increase marginal abatement costs of CDM host countries by inducing an upward shift of the CDM supply curve.

As a second barrier to CDM investments we account for investment risk involved in financing carbon-abatement projects. Following Böhringer and Löschel (2002), host-country-specific investment risk for CDM projects, e.g. resulting from country and project risks, is derived by regional bond-yield spreads between long-term government bonds of the respective developing country and the United States (as a risk-free reference region). It is assumed that investors are risk-neutral and discount emissions reduction credits generated by CDM projects with the mean risk value of the respective host country. The underlying data is based on the International Monetary Fund's International Financial Statistics (IMF, 2000). In our quantitative model framework, investment risk reduces the generated CDM credit volume,

\footnotetext{
${ }^{3}$ Excess emissions permits (so-called "Hot Air") are due to lower projected baseline emissions than the target level implied by Russia's reduction commitment in 2020. We abstract from "Hot Air" here, as a grandfathered allowance allocation of "Hot Air" would imply an indirect subsidy for Russian installations (the allocated permits could be directly exported to other ETS regions). It is not unambiguous if such an ETS design may prevail or even be linked to an EU scheme.

${ }^{4}$ The magnitude of transaction costs is consistent with recent estimations (Michaelowa and Jotzo, 2005).
} 
thereby lowering the revenue of CDM projects and effectively inducing a leftward rotation of the CDM supply curve.

\section{$4 \quad$ Policy scenarios}

In order to assess the competitiveness impacts of linking the EU ETS to emerging schemes outside Europe, we introduce alternative policy scenarios for the year 2020. Across all scenarios, the regulation stringency is represented by the underlying regional emissions reduction targets and the respective allowance allocation as presented in the previous section. Within the European and emerging non-European emissions trading schemes, the covered (ETS) sectors are assumed to be allocated tradable allowances, while the remaining (NETS) industries have to be regulated via domestic abatement measures (here: unilateral carbon taxation) in order to meet the national emissions reduction targets in $2020 .^{5}$ In our analysis, emissions trading at the installation level is, thus, approximated by sectoral trading activities. Moreover, all regions that have not (yet) set up an emissions trading scheme are assumed to comply with their emissions reduction target by cost-efficient domestic emissions regulation, imposing a uniform carbon tax on the entire economy. Table 1 presents the set of policy scenarios of our analysis, showing the corresponding constellations of linking the EU ETS internationally. As a reference case, scenario EU represents the current EU trading scheme, while all non-EU linking candidates fulfill their Kyoto commitment by domestic action. Scenario $\mathrm{EU}^{+}$indicates the potential linkage of the current EU ETS to emerging schemes in two countries that have ratified the Kyoto Protocol, namely Japan and Canada. Scenario $E U^{++}$ assumes that the Kyoto-ratifier Russia is joining the system of the EU-27, Canada and Japan. Finally, the most optimistic scenario $E U^{+++}$implies linking the EU ETS also to emerging trading schemes in the non-ratifying Annex B countries United States and Australia.

\footnotetext{
${ }^{5}$ Note that for the emissions trading schemes of all linking candidates we assume an identical sectoral coverage to the EU ETS, as well as the regulation of $\mathrm{CO}_{2}$ as the only greenhouse gas.
} 
Table 1: Policy scenarios in 2020 and CDM host countries

\begin{tabular}{|c|c|c|}
\hline Regional scenario & $\begin{array}{l}\text { Regions participating in } \\
\text { emissions trading }\end{array}$ & CDM regions \\
\hline $\boldsymbol{E} \boldsymbol{U}$ & EU-27 & \multirow{4}{*}{$\begin{array}{c}\text { China } \\
\text { India } \\
\text { Rest of East South Asia } \\
\text { Brazil } \\
\text { Central + South America } \\
\text { South Africa }\end{array}$} \\
\hline $\boldsymbol{E} \boldsymbol{U}^{+}$ & $\begin{array}{c}\text { EU-27 } \\
\text { Japan } \\
\text { Canada }\end{array}$ & \\
\hline $\boldsymbol{E} \boldsymbol{U}^{++}$ & $\begin{array}{c}\text { EU-27 } \\
\text { Japan } \\
\text { Canada } \\
\text { Russian Federation }\end{array}$ & \\
\hline$E \boldsymbol{U}^{+++}$ & $\begin{array}{c}\text { EU-27 } \\
\text { Japan } \\
\text { Canada } \\
\text { Russian Federation } \\
\text { United States } \\
\text { Australia }\end{array}$ & \\
\hline
\end{tabular}

The amending directive linking the European ETS with the Kyoto Protocol's project-based mechanisms enables European companies (here: the ETS sectors) to generate emissions reductions in developing countries by means of the CDM and using the respective credits as a substitute for EU allowances (EU, 2004). We cover this regulation by introducing CDM access for European ETS sectors (denoting this scenario as EU_CDM) and adopt it for all linking candidates. By concentrating on private CDM investments only, we abstract from government CDM activities as facilitated under the Kyoto Protocol. ${ }^{6}$ Table 1 shows that for all regional scenarios alike six central developing regions are assumed to host CDM projects, representing major suppliers on the CDM carbon market (World Bank, 2006). As described in the previous section, our CDM representation considers transaction costs and investment risk as central barriers to CDM investments. In our subsequent comparative-static analysis we measure the macroeconomic impacts of climate policy in 2020 relative to the benchmark situation - usually termed Business-as-Usual (BaU) - where no emissions regulation is imposed.

\footnotetext{
${ }^{6}$ For a macroeconomic impact assessment of government CDM under the Kyoto Protocol see Anger et al. (2007).
} 


\section{$5 \quad$ Simulation results}

This section presents the simulation results of our model-based assessment of the macroeconomic and competitiveness impacts of linking the EU ETS internationally. The corresponding quantitative simulation results are presented in Table 6 and Table 7 of Appendix 8.5. We start our analysis by reporting the effects of linking the EU ETS on the market for emissions permits (section 5.1) and the associated macroeconomic impacts (section 5.2), before addressing the competitiveness effects of linking the European trading scheme (section 5.3). Finally, we present a sensitivity analysis with respect to the assumed allowance allocation (section 5.4).

\subsection{Impacts on the emissions market}

Regarding the effects of linking the EU ETS on the market for emissions permits, Figure 4 first shows that the international permit price resulting from a European emissions trading scheme in 2020 (scenario $E U$ ) amounts to $26.36 €$ per ton $\mathrm{CO}_{2}$ assuming an empirical allowance allocation (see section 3.2). The figure further illustrates that linking the EU system to emerging schemes substantially decreases the $\mathrm{CO}_{2}$ value in the covered sectors: Despite of the relatively high-cost abatement options of Canada and Japan, the relatively generous allowance allocation in both countries - i.e. an allocation factor equal to 0.90 - induces a lower permit price in the linked scheme (yielding scenario $E U^{+}$), amounting to $21.17 €$.

A further integration of Russia (scenario $E U^{++}$) increases the where-flexibility of emissions abatement and puts more downward pressure on the allowance price, amounting to $14.27 €$. Note that we assume an allocation factor equal to one for Russia, so that we abstract from the assignation of potential excess emissions permits to the covered Russian installations in our scenario setting. Hence, the lower permit price in scenario $E U^{++}$originates from relatively low-cost abatement options of permit-exporting Russian ETS sectors. Further linking of the EU ETS to the non-ratifiers Australia and the United States (scenario $E U^{++}$) induces an additional permit price fall to $8.24 €$ per ton $\mathrm{CO}_{2}$. Despite of the generally high-cost abatement options in Australia and the Unites States, the generously assignation of emissions (allocation factor equal to 0.95) implies that these regions exhibit relatively low marginal abatement cost levels as compared to the other participants. The corresponding permit supply from these countries further decreases the international permit price. 


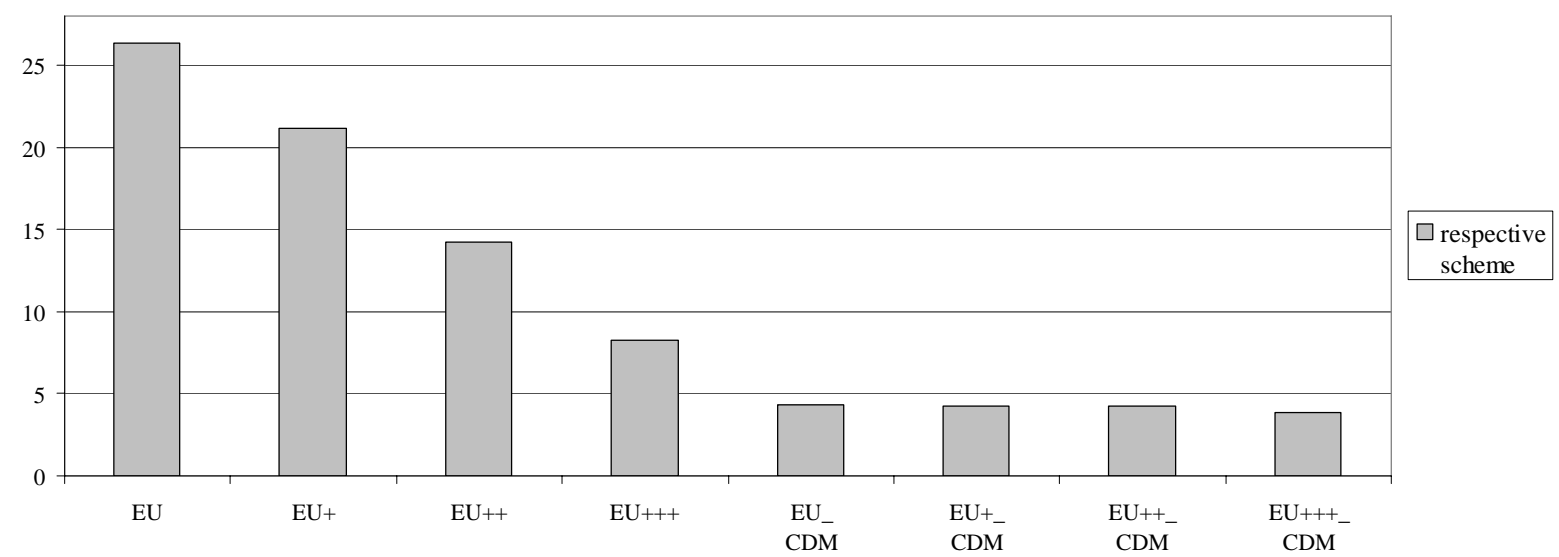

Figure 4: $\mathrm{CO}_{2}$ permit price within linked schemes by scenario

Across all linking scenarios, allowing the covered ETS sectors to import low-cost emissions reductions from developing countries via the CDM substantially lowers the international $\mathrm{CO}_{2}$ value. The maximum price in this case amounts to $4.32 €$ in a purely European system, while the most integrated scheme including Australia and the United States generates the lowest value of 3.87€. According to Figure 4, establishing CDM access for ETS sectors levels out the permit price differences between alternative linking strategies.

\subsection{Macroeconomic impacts}

From a general equilibrium perspective, the economic effects of climate change policies surpass the emissions market. First, carbon abatement policies may decrease domestic production levels by the associated decreased energy use due to increased domestic abatement or a policy-induced increased permit price. Second, in large open economies policy-induced carbon restrictions induce changes in exports and imports, most dominantly on fossil fuel markets, thereby affecting international prices and the regional terms of trade (Böhringer and Rutherford, 2002). In order to analyze these general equilibrium (i.e. multi-market) impacts from climate policy in greater detail, in the following we assess aggregate macroeconomic indicators such as production and social welfare. ${ }^{7}$

\footnotetext{
${ }^{7}$ Note that we pursue a cost-effectiveness analysis that quantifies adjustment costs of environmental regulation as compared to an unconstrained business-as-usual situation. The deliberate neglect of economic benefits from controlling global warming implies that the macroeconomic effects resulting from the imposition of emissions constraints on the respective economies will necessarily be negative. Welfare changes are expressed by the
} 
Table 6 of Appendix 8.5 shows that for the EU-27, production and welfare impacts of emissions regulation in a purely European trading scheme amount to roughly three percent. While these macroeconomic impacts do not change significantly by linking the EU ETS to Canada, Japan and Russia, the maximum where-flexibility of emissions abatement in scenario $\mathrm{EU}^{+++}$slightly reduces production and welfare losses. Moreover, it shows that accounting for CDM access does not change the welfare impacts across scenarios substantially: Especially in the linked scheme $E U^{+++}$the access to low-cost emissions abatement via the CDM for only a part of European economies (i.e. the covered sectors) cannot induce substantial efficiency improvements, as the participating regions already benefit from a high where-flexibility by linking their schemes.

For those non-EU regions which are not (yet) involved in linked emissions trading schemes we assume compliance with the national emissions reduction targets (see Table 2 of Appendix 8.1) by means of unilateral economy-wide carbon taxation. Thereby, we are able to measure the economic implications for these countries of linking to the European system against the consistent reference scenario of cost-efficient domestic action. For our policy scenarios, Table 6 shows heterogeneous macroeconomic impacts across non-EU countries. These differences originate from diverging national emissions reduction targets, permit allocation stringencies and emissions abatement options. Moreover, all regions with effective emissions reduction requirements (except of the United States) face substantially higher welfare costs when linking to the EU scheme as compared to domestic action: On pure efficiency grounds, the assumed design of emissions trading schemes is inferior to the reference case of cost-efficient domestic action. The central reason is that a generous allowance allocation to the covered ETS sectors implies the imposition of high emissions reduction efforts of the non-covered sectors. In the absence of the CDM, these industries - having relatively high-cost abatement options (e.g. in the household or transport sector) - have to be regulated by costly complementary domestic carbon taxation in order to achieve the national emissions reduction targets.

As for the European economies, the welfare impacts for most non-EU regions do not vary significantly across linking and CDM scenarios. However, Table 6 shows that permitexporting Russia substantially benefits from linking to the joint scheme of the EU-27, Canada and Japan. These benefits are cancelled out again if also Australia and the United States join the international trading scheme, introducing a permit-price decreasing where-flexibility. The

Hicksian Equivalent Variation (HEV). The welfare indicator thereby summarizes both economic impacts on the emissions market as well as macroeconomic impacts. 
same reasoning may be applied if CDM access for the covered ETS sectors facilitates the inflow of competing low-cost permits from developing countries into the trading system.

\subsection{Effects on international competitiveness}

In this section, we assess the national and sectoral competitiveness effects of linking EU Emissions Trading Scheme with emerging schemes outside Europe. The corresponding numerical simulation results are presented in Table 7 of Appendix 8.5.

\section{Competitiveness effects for the EU}

Focusing first on EU Member States, Figure 5 (a) reports economy-wide competitiveness effects as measured by changes in the terms of trade (ToT) - i.e. the ratio between export and import prices - across alternative policy scenarios. The figure illustrates that - consistent with our findings on welfare impacts - linking the EU ETS internationally does not substantially affect the national competitiveness for EU Member States. However, the ToT losses of EU economies in a purely domestic European scheme (scenario $E U$ ) are slightly increased from 3.1 to -3.3 percent by integrating Canada, Japan and Russia (yielding scenario $E U^{++}$), while economy-wide competitiveness can be improved to -2.9 percent by opening the European trading system to all linking candidates (yielding scenario $E U^{+++}$). Again these findings do not significantly change by the introduction of CDM access for the covered industries.

In order to decompose the national competitiveness impacts for EU Member States, we assess sectoral competitiveness effects using two well-known indicators: Revealed Comparative Advantage (RCA) and Relative World Trade Shares (RWS). ${ }^{8}$ Note that the two indicators may be used complementarily in assessing the sectoral ability to compete, as they measure competitiveness implications using different reference points: The RCA indicator compares the trade performance of an ETS (NETS) sector with the performance of all sectors within the respective region. The RWS indicator relates the trade performance of an ETS (NETS) sector in a region to the performance of ETS (NETS) sectors across the world.

\footnotetext{
${ }^{8}$ A detailed description of the employed competitiveness indicators is given in Appendix 8.4.
} 
Terms of Trade impacts for primary linking candidates (in \% vs. BAU)

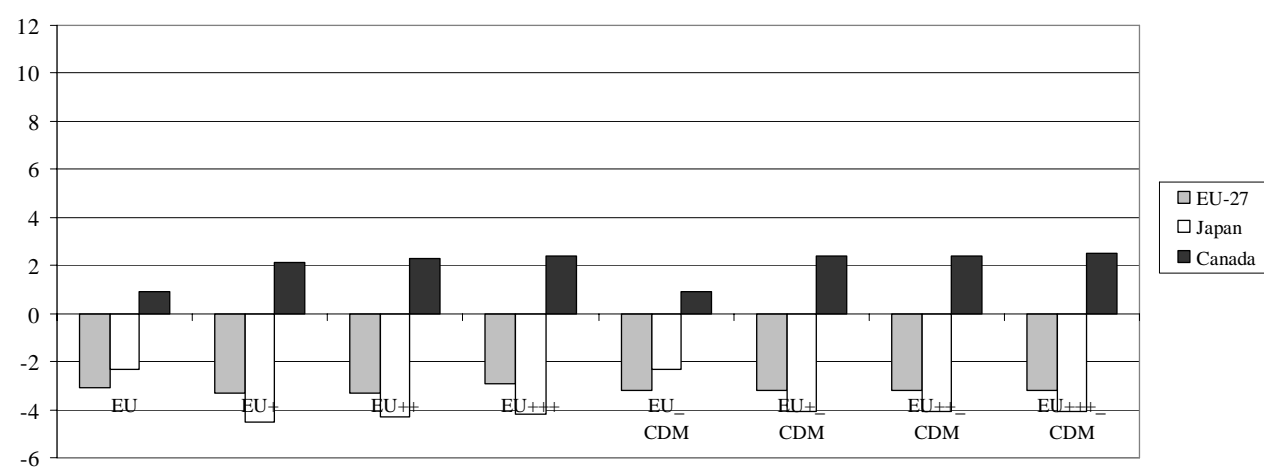

(a)

Revealed Comparative Advantage (RCA) for EU industries (in \% vs BAU)

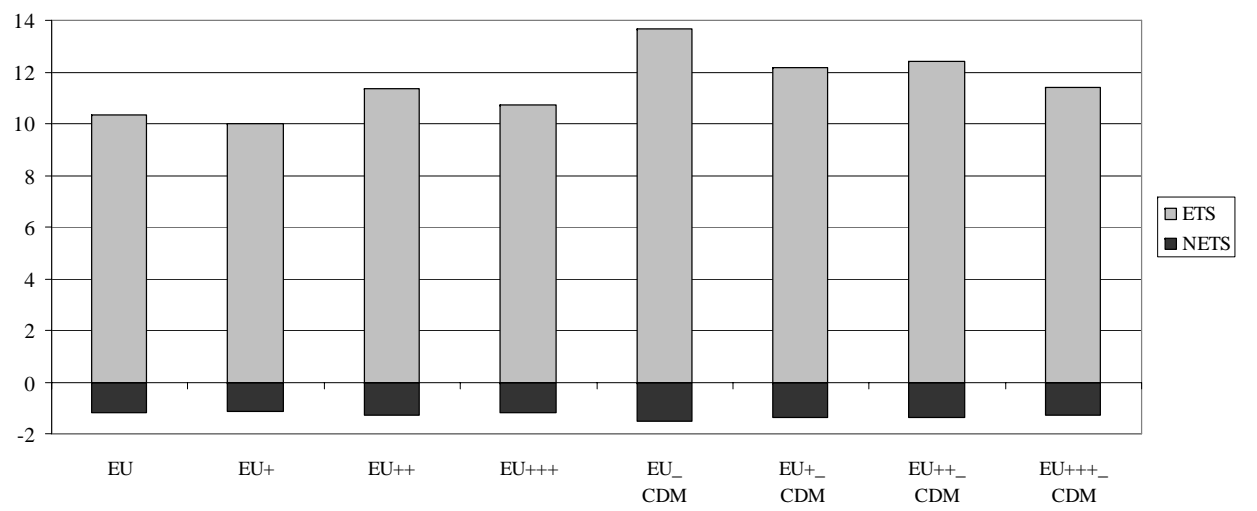

(c)
Terms of Trade impacts for secondary linking candidates (in \% vs. BAU)

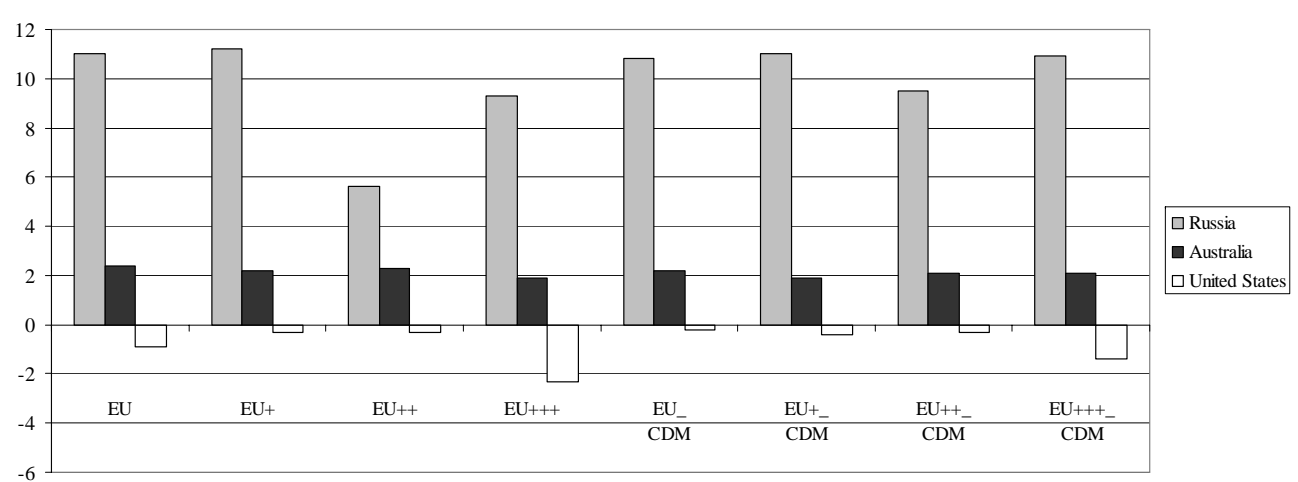

(b)

Relative World Trade Shares (RWS) for EU industries (in \% vs BAU)

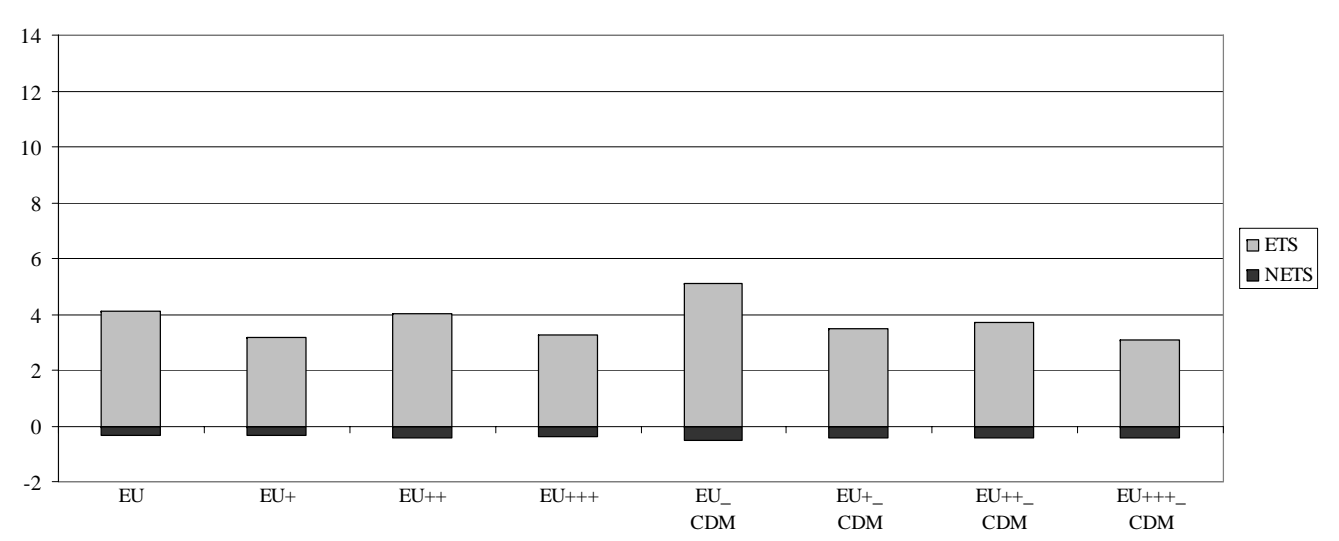

(d)

Figure 5: Economy-wide and sectoral competitiveness indicators by region, sector and scenario 
While the economy-wide impacts across policy scenarios are limited, the sectoral competitiveness implications show a differentiated picture. Firstly, Figure 5 (c) and (d) illustrate that in a purely European trading scheme (scenario EU), the covered European ETS sectors exhibit large competitiveness gains vis-à-vis the remaining EU industries - the corresponding RCA indicator amounting to as much as 10.32 percent. This result is due to a relatively generous allowance allocation to these sectors and the corresponding high complementary domestic carbon taxation on NETS industries which have costly abatement options. Thus, the NETS industries account for the major economic compliance burden and face competitiveness losses vis-à-vis the ETS sectors. Moreover, in a purely EU trading scheme the European ETS sectors exhibit competitiveness gains vis-à-vis comparable sectors in non-EU regions, however at a lower level (the corresponding RWS indicator amounting to only 4.13 percent). This competitiveness improvement of the European ETS sectors is due to the fact that comparable sectors in non-EU regions are burdened by domestic emissions regulation in this policy setting.

Secondly, Figure 5 (c) and (d) suggest that the RWS varies similarly to the RCA indicator for linking scenarios of the EU ETS, only at a lower level: By linking to emerging schemes in Japan and Canada, the sectors covered by the European trading scheme may face slight decreases in their competitiveness both vis-à-vis NETS industries within the EU (RCA) and comparable ETS sectors in non-EU regions (RWS). Here, the RWS loss of European ETS sectors reflects the competitiveness improvement of the same sectors in Canada and Japan: The introduction of an emissions trading scheme with a generous allowance allocation implies a preferential treatment of their ETS sectors as compared to cost-efficient domestic action. Furthermore, the RCA loss of European ETS sectors vis-à-vis the European NETS sectors is due to general equilibrium effects on international trade: The introduction of inefficient emissions trading schemes in Canada and Japan implies an excessive burden shifting from ETS to NETS sectors in these countries. As a consequence, the (competing) European NETS sectors increase their international export activity and thus improve their competitiveness also vis-à-vis the European ETS sectors. While the European ETS industries face competitiveness losses through linking to Japan and Canada, we generally observe opposite (and less pronounced) effects for the non-covered European NETS sectors.

Further regional flexibility in emissions trading through a linkage to low-cost permit supplier Russia may, however, substantially counteract the competitiveness losses of European ETS sectors as compared to regional scenario $\mathrm{EU}^{+}$. In particular, we observe competitiveness gains for the European ETS sectors as compared to regional scenarios $E U$ and $E U^{+}$. Further 
integrating Australia and the United States (scenario $E U^{+++}$) implies a slight decrease in competitiveness for European ETS sectors vis-à-vis comparable industries in non-EU regions (RWS). These results can be explained analogously to our above findings for linking to Japan and Canada.

Figure 5 (c) and (d) illustrate that for each linking strategy, CDM access for ETS sectors serves as a flexibility instrument that improves the sectoral competitiveness effects for these industries both vis-à-vis the remaining sectors of EU economies and comparable sectors in non-EU regions. On the contrary, it shows that the non-covered NETS sectors are not able to improve their international competitiveness as they are excluded from the low-cost abatement options of the CDM.

\section{Competitiveness effects for linking candidates}

Figure 5 (a) and (b) summarize the prospects for the non-EU linking candidates of joining the European trading system in terms of national competitiveness impacts. ${ }^{9}$ While linking the EU ETS to Japan and Canada (yielding scenario $E U^{+}$) induces a further increase of the initial economy-wide competitiveness for Canada in scenario $E U$, Japan is facing a further decrease in its ToT. These heterogeneous results can be explained as follows: A linkage to Japan and Canada implies the introduction of an inefficient domestic emissions regulation in both countries. As mentioned above, these inefficiencies are due to the relatively generous allowance allocation and the associated abatement-burden shifting to the non-covered NETS sectors of these regions. Such a policy design implies competitiveness gains for ETS sectors and competitiveness losses for NETS sectors in both countries. However, the induced burdenshifting from covered to non-covered sectors is more pronounced in Japan than in Canada. As a consequence, in Japan overall export (import) values are decreasing (increasing) and the ToT further deteriorate through linking to the European ETS. In contrast, Canada is able to increase (decrease) its overall export (import) values and can thus benefit from linking to the EU in terms of overall competitiveness. Here, the reason is a strong competitiveness improvement in the energy-intensive sectors covered by the Canadian trading system. These industries are benefiting to a large extent from linking to the low-priced European system, as they faced a relatively high domestic carbon tax before linking to the EU.

\footnotetext{
${ }^{9}$ Note that all numerical sectoral competitiveness impacts for non-EU regions can be found in Table 7 of Appendix 8.5.
} 
A further linkage to permit-exporting Russia (yielding scenario $E U^{++}$) slightly improves the ToT situation of the permit importers Canada and Japan, but substantially decreases the competitiveness gains of Russia itself. Here, the newly linked Russia has an incentive to reduce emissions at relatively low marginal cost in order to export permits to the emissionstrading partners. These adjustments in the Russian economy induce negative feed-back effects in terms of a decreased international fossil-fuel demand and price, subsequently deteriorating the ToT of energy-exporting Russia. Finally, a further integration of Australia and the United States (yielding scenario $\mathrm{EU}^{+++}$) decreases the national-wide competitiveness of both linking candidates due to the introduction of an inefficient domestic emissions regulation also in these countries. However, the Russian ToT are increasing again in this policy scenario. In general, allowing for CDM imports to the covered ETS sectors leaves these qualitative findings unchanged.

Summarizing our findings from an incentive perspective, in the absence of the CDM both the European Union and Canada improve their economy-wide competitiveness by linking their emissions trading schemes to all linking candidates (yielding scenario $E U^{+++}$). On the other hand, both Russia and United States benefit most from a joint trading scheme between the EU-27, Canada and Japan (scenario $E U^{+}$). For their part, Japan and Australia loose competitiveness - compared to cost-efficient domestic action - by establishing and linking their emissions trading systems internationally. However, from the set of alternative trading schemes, Australia prefers a joint system between the EU-27, Japan, Canada and Russia (scenario $E U^{++}$), while Japan would opt for linking up to all candidates. In summary, we observe a large regional heterogeneity regarding the incentives for establishing alternative supra-European emissions trading schemes.

\subsection{Sensitivity analysis: Proportional allowance allocation}

While the allocation of emissions permits to the covered sectors in future trading schemes is crucial for our simulation results, it clearly underlies a considerable uncertainty. In the following we therefore present a sensitivity analysis with respect to the stringency of allowance allocation. In contrast to the empirically motivated allocation factors (see sections 3.2 and 5.3) we now assume that the covered sectors of a domestic trading system have to reduce their emissions proportionally to the national effective emissions reduction target. In contrast to the preferential treatment of ETS sectors under the original allowance allocation, in this case the covered industries equitably contribute to the national abatement efforts. For example, a region with an effective emissions reduction target of 40 percent versus $\mathrm{BaU}$ in 
2020 would allocate an amount of emissions allowances to the covered sectors which corresponds to an allocation factor of 0.6. This rule implies a stricter allocation to the covered sectors as compared to the empirically based allocation factors.

The simulation results of our sensitivity analysis are presented in Table 8 and Table 9 of Appendix 8.5. It shows that the stricter allowance allocation induces a higher permit price within the EU ETS, amounting to $31.73 €$ per ton of $\mathrm{CO}_{2}$. In contrast to our previous findings, the proportional permit allocation induces a slightly increased permit price (to $33.68 €$ ) by linking the European scheme to Canada and Japan. This price increase is, however, substantially counteracted by linking to the permit exporter Russia, which decreases the $\mathrm{CO}_{2}$ value to $20.54 €$, and further to $15.27 €$ by integrating Australia and the United States.

We find that the overall level of welfare losses due to emissions regulation and the associated economy-wide competitiveness effects are far less pronounced in the case of a stricter allowance allocation, improving efficiency within the trading schemes for all linking scenarios. In particular, the former negative welfare impacts for non-EU linking candidates from establishing an inefficient domestic trading scheme are substantially diminished, thereby increasing the attractiveness of the linking process for these countries. While our economywide competitiveness results do not differ significantly from our findings in the previous section, we conclude that the competitiveness impacts for the European ETS sectors of linking the EU system are amplified in the case of proportional allowance allocation: While linking to Canada and Japan is even more disadvantageous, the partly positive previous competitiveness effects of integrating Russia, Australia and the United States are improved substantially both vis-à-vis the remaining EU sectors and comparable industries in non-EU regions.

\section{Conclusions}

Given the coexistent EU priorities concerning the competitiveness of European industries and ambitious international emissions regulation at the company level, this paper presents an efficiency and international trade analysis of developing supra-European emissions trading schemes. In order to achieve its climate policy objectives more cost-efficiently, the EU currently proposes to strengthen the EU Emissions Trading Scheme (ETS) by linking to emerging domestic trading systems outside Europe, e.g. in Canada, Japan and Australia. The EU ETS may thus form the nucleus for a gradually expanding global carbon market that enables international emissions trading at the company level. 
Employing both economic theory and numerical model simulations, we first discuss the efficiency aspects of integrating emissions trading schemes within a partial analytical framework. Our stylized analysis suggests that - independently of the marginal abatement costs of a region to be linked with an existing scheme - the integration of trading systems yields economic efficiency gains for all participating regions. This result is due to the increased where-flexibility of regional emissions abatement. We subsequently analyze the macroeconomic and trade-based competitiveness impacts of linking the EU ETS employing a large-scale computable general equilibrium model of the global economy.

Based on empirical allowance allocation of the EU ETS, we find that while linking the EU system internationally may substantially decrease the international permit price, the associated aggregate welfare impacts for the EU are rather limited. As the efficiency gains from an international linkage exclusively apply to those sectors which are covered by the linked trading schemes, the remaining sectors will not benefit from an increased where-flexibility. For non-EU countries, establishing an inefficient trading system may induce substantial welfare losses - due to a too generous allowance allocation to the covered sectors - which may be compensated only partially through linking to the EU trading scheme. Accounting for permit imports from outside the linked schemes via the Clean Development Mechanism (CDM) does not alter these welfare impacts substantially: The access to low-cost emissions abatement in developing countries for only a part of the economy (i.e. the covered sectors) cannot induce substantial aggregate efficiency improvements - especially in the case of linking all candidates, as the participating regions already benefit from a high whereflexibility.

We find that - consistent with the insights from our welfare analysis - linking the EU ETS internationally does not substantially affect economy-wide EU competitiveness as measured by the terms of trade. However, the trade-based competitiveness effects crucially depend on the linked trading system: Although EU economy-wide competitiveness varies only moderately across linking scenarios, the sectoral decomposition of these aggregate effects shows that European industries are much more sensitive to the linking constellation. By integrating emerging schemes in Japan and Canada, those sectors covered by the European trading scheme may face competitiveness losses both vis-à-vis the non-covered industries within the EU and comparable sectors in non-EU regions. These effects are due to the introduction of inefficient emissions trading schemes in Canada and Japan. Further regional flexibility in emissions trading through a linkage to low-cost permit supplier Russia may, however, substantially counteract the negative sectoral competitiveness impacts on the 
covered European industries. Finally, a future integration of Australia and the United States into a joint trading system of all linking candidates keeps the competitiveness losses for European ETS sectors at a moderate level.

Regarding the international trade impacts for non-EU countries, we find that the linking candidates have very heterogeneous incentives to join the European trading system, which range from pronounced competitiveness improvements for Canada to substantial competitiveness losses for Japan. Our sensitivity analysis assuming a stricter allowance allocation within regional trading systems suggests, however, that a more efficient design of domestic ETS can boost the overall prospects for establishing supra-European emissions trading schemes. 


\section{$7 \quad$ References}

Anger N, Böhringer C, Moslener U (2007) Macroeconomic Impacts of the Clean Development Mechanism: The Role of Investment Barriers and Regulations. ZEW Discussion Paper No. 07-026, Mannheim

Anger N (2006) Emissions Trading Beyond Europe: Linking Schemes in a Post-Kyoto World. ZEW Discussion Paper No. 06-058, Mannheim

Armington P S (1969) A Theory of Demand for Producers Distinguished by Place of Production. IMF Staff Papers 16: 159-178

Blyth W, Bosi M (2004) Linking Non-EU Domestic Emissions Trading Schemes with the EU Emissions Trading Scheme. http://www.oecd.org/dataoecd/38/7/32181382.pdf. Cited 05 June 2007

Böhringer C, Hoffmann T, Lange A, Löschel A, Moslener U (2005) Assessing Emissions Regulation in Europe: An Interactive Simulation Approach. The Energy Journal 26(4): $1-22$

Böhringer C, Löschel A (2002) Risk and Uncertainty in Project-based Emissions Crediting. In: Van Ierland E C, Weikard H P, Wesseler J (eds) Risk and Uncertainty in Environmental and Resource Economics. Conference Proceedings, Wageningen University, Wageningen, 5-7 June 2002

Böhringer C, Rutherford T F (2002) Carbon Abatement and International Spillovers. Environmental and Resource Economics 22(3): 391-417.

Böhringer C, Vogt C (2003) Economic and Environmental Impacts of the Kyoto Protocol. Canadian Journal of Economics 36: 475-494

CEPA Environmental Registry (2005) Notice of intent to regulate greenhouse gas emissions by Large Final Emitters. Canada Gazette Part I, vol 139 no 29

Conrad, K (1999) Computable General Equilibrium Models for Environmental Economics and Policy Analysis. In: van den Bergh, J C J M (ed) Handbook of Environmental and Resource Economics. Edward Elgar, Cheltenham, pp1061-1087

Conrad, K (2001) Computable General Equilibrium Models in Environmental and Resource Economics. In: Tietenberg $\mathrm{T}$, Folmer $\mathrm{H}$ (eds) International Yearbook of Environmental and Resource Economics 2002/2003. Edward Elgar, Cheltenham, pp66-114 
Dimaranan B V, McDougall R A (2006) Global Trade, Assistance, and Production: The GTAP 6 Data Base. Center for Global Trade Analysis, Purdue University, WestLafayette

EU (2000) Presidency Conclusions - Lisbon European Council: 23 and 24 March 2000.

Council of the European Union, Brussels.

http://europa.eu.int/ISPO/docs/services/docs/2000/jan-march/doc_00_8_en.html. Cited 05 June 2007

EU (2003) Directive Establishing a Scheme for Greenhouse Gas Emissions Allowance

Trading within the Community and Amending Council. Directive 96/61/EC. European Commission, Brussels. http://eur-

lex.europa.eu/LexUriServ/site/en/oj/2003/1_275/1_27520031025en00320046.pdf.

Cited 05 June 2007

EU (2004) Directive 2004/101/EC, amending Directive 2003/87/EC establishing a scheme for greenhouse gas emissions allowance trading within the Community, in respect of the Kyoto Protocol’s project mechanisms. European Commission, Brussels. http://europa.eu.int/comm/environment/climat/emission/pdf/dir_2004_101_en.pdf. Cited 05 June 2007

EU (2005) 28th EP/Canada Interparliamentary Meeting, 29 - 30 March 2005, Report from the Chairman, Mr Seán Ó Neachtain. European Parliament, Brussels. www.europarl.europa.eu/meetdocs/2004_2009/documents/fd/200/200501/20050119_0 01en.pdf. Cited 05 June 2007

EU (2007a) Limiting Global Climate Change to 2 degrees Celsius - The way ahead for 2020 and beyond. European Commission, Brussels. http://ec.europa.eu/environment/climat/future_action.htm. Cited 05 June 2007

EU (2007b) An energy policy for Europe, SEC(2007) 12. European Commission, Brussels. http://ec.europa.eu/energy/energy_policy/doc/01_energy_policy_for_europe_en.pdf. Cited 05 June 2007

EU (2007c) National Allocation Plans: Second Phase (2008-2012). http://ec.europa.eu/environment/climat/2nd_phase_ep.htm. Cited 05 June 2007 EU-Japan Centre for Industrial Cooperation (2006) Seminar on "Review of the EU Emissions Trading Scheme (EU ETS) and its Future Developments”. 14 December 2006, Brussels. 
www.eujapan.com/japan/MainPoints\%20of\%20the\%2012th\%20seminar.pdf. Cited 05 June 2007

IMF (2000) IMF International Financial Statistics. http://ifs.apdi.net/imf/. Cited 05 June 2007 Japanese Ministry of the Environment (2004) Evaluation of the Pilot Project of Domestic Emissions Trading Scheme. http://www.env.go.jp/en/earth/cc/040707.pdf. Cited 05 June 2007

Kemfert C, Kohlhaas M, Truong T, Protsenko A (2005) The Environmental and Economic Effects of European Emissions Trading. DIW Discussions Papers 533, Berlin

Klepper G, Peterson, S (2004) The EU Emissions Trading Scheme, Allowance Prices, Trade Flows, Competitiveness Effects. Kiel Working Paper no 1195, Kiel Institute for World Economics, Kiel

Kruger J, Oates W E, Pizer W A (2007) Decentralization in the EU Emissions Trading Scheme and Lessons for Global Policy. RFF Discussion Paper 07-02, Washington Michaelowa A, Jotzo F (2005) Transaction costs, institutional rigidities and the size of the clean development mechanism. Energy Policy 33 (4): 511-523

New South Wales Government (2006) Greenhouse Gas Abatement Scheme (GGAS). http://www.greenhousegas.nsw.gov.au/. Cited 05 June 2007

Peterson S (2006a) Efficient Abatement in Separated Carbon Markets: A Theoretical and Quantitative Analysis of the EU Emissions Trading Scheme. Kiel Working Paper no 1271, Kiel Institute for World Economics, Kiel

Peterson S (2006b) The EU Emissions Trading Scheme and its Competitiveness Effects upon European Business Results from the CGE Model DART. Mimeo, Kiel Institute for World Economics, Kiel

Point Carbon (2006) Australian States propose 20-year emissions cap and trade scheme. Carbon Market News, 16 August 2006

RGGI (2006) The Regional Greenhouse Gas Initiative. http://www.rggi.org/. Cited 05 June 2007

Sterk W, Braun M, Haug C, Korytarova K, Scholten A (2006) Ready to link up? Implications of Design Differences for Linking Domestic Emissions Trading Schemes. JET-SET Working Paper I/06, Wuppertal Institute for Climate, Environment and Energy, 
Wuppertal. http://www.wupperinst.org/uploads/tx_wibeitrag/ready-to-link-up.pdf. Cited 05 June 2007

Sterk W (2005) Ready to link up? The EU and the international carbon market. Carbon Market Europe, 28 October 2005

UNFCCC (1997) Kyoto Protocol to the United Nations Framework Convention on Climate Change. United Nations Framework Convention on Climate Change, FCCC/CP/L.7/Add1, Kyoto

US Department of Energy (2005) International Energy Outlook, Energy Information Administration

World Bank (2006) State and Trends of the Carbon Market 2006. World Bank Report, Washington DC 


\section{Appendix}

\subsection{Benchmark data sources}

The main data source underlying our model assessment is the GTAP version 6 database that represents global production and trade data for 87 regions and 57 sectors in the baseyear 2001 (Dimaranan and McDougall, 2006). For this application, the data set has been aggregated to 36 regions and 10 sectors in order to reduce the dimensionality of the computational problem, but at the same time keep sufficient detail for the carbon-relevant regions and sectors (see Table 3 and Table 4 in Appendix 8.2). Reconciliation of these data sources yields the benchmark data of our model.

In a second step, we perform a forward calibration of the 2001 economies to the target year 2020. For this purpose we employ baseline estimates for GDP growth, energy demand and future energy prices as well as carbon emissions, relying on energy trends for EU Member States (EU, 2003) and on international energy projections for non-European economies (US Department of Energy, 2005). The magnitude and distribution of costs associated with the implementation of future emissions constraints depend on the baseline projections for GDP, fuel prices, energy efficiency improvements etc. In our comparative-static framework, we measure the costs of abatement relative to a baseline, i.e. relative to the benchmark situation usually termed Business-as-Usual (BaU), where no emissions regulation is imposed. As an overview on the emissions data underlying our analysis, Table 2 shows baseline emissions and reduction requirements of Annex-B countries in 2010 and 2020. For the year 2010 we present the targets under the Kyoto Protocol, while for 2020 we assume the future commitments as laid out in section 3.2. Contrasting regional baseline carbon emissions in the respective year to the regional emissions reduction target vs. 1990 emissions yields the effective emissions reduction requirement of a region. 
Table 2: Baseline emissions and reduction requirements of ratifying Annex-B countries

\begin{tabular}{|c|c|c|c|c|c|c|c|}
\hline \multirow[b]{2}{*}{ Year } & \multicolumn{3}{|c|}{$\begin{array}{c}\text { Baseline } \mathrm{CO}_{2} \text { Emissions } \\
\left(\mathrm{Mt} \text { of } \mathrm{CO}_{2}\right)\end{array}$} & \multicolumn{2}{|c|}{$\begin{array}{c}\text { Emissions reduction } \\
\text { target (\% vs. 1990) }\end{array}$} & \multicolumn{2}{|c|}{$\begin{array}{c}\text { Effective reduction } \\
\text { requirement ( } \% \text { vs. baseline) }\end{array}$} \\
\hline & 1990 & 2010 & 2020 & 2010 & 2020 & 2010 & 2020 \\
\hline Austria & 55.1 & 60.7 & 66.7 & 13.0 & 24.3 & 21.0 & 37.5 \\
\hline Belgium & 106.3 & 112.2 & 120.1 & 7.5 & 19.5 & 12.4 & 28.8 \\
\hline Denmark & 52.8 & 46.6 & 45.0 & 21.0 & 31.3 & 10.5 & 19.4 \\
\hline Finland & 53.2 & 51.4 & 55.7 & 0.0 & 13.0 & -3.5 & 16.9 \\
\hline France & 354.1 & 406.4 & 447.9 & 0.0 & 13.0 & 12.9 & 31.2 \\
\hline Germany & 943.0 & 823.6 & 869.8 & 21.0 & 31.3 & 9.5 & 25.5 \\
\hline United Kingdom & 569.1 & 519.4 & 559.0 & 12.5 & 23.9 & 4.1 & 22.5 \\
\hline Greece & 71.1 & 105.6 & 112.2 & -25.0 & -8.8 & 15.8 & 31.1 \\
\hline Ireland & 29.7 & 46.5 & 48.7 & -13.0 & 1.7 & 27.8 & 40.0 \\
\hline Italy & 390.8 & 422.2 & 437.4 & 6.5 & 18.7 & 13.5 & 27.3 \\
\hline Netherlands & 152.9 & 174.0 & 184.4 & 6.0 & 18.2 & 17.4 & 32.2 \\
\hline Portugal & 39.0 & 67.9 & 80.4 & -27.0 & -10.5 & 27.1 & 46.4 \\
\hline Spain & 203.8 & 302.6 & 335.7 & -15.0 & 0.0 & 22.5 & 39.3 \\
\hline Sweden & 50.6 & 54.0 & 68.3 & -4.0 & 9.5 & 2.5 & 33.0 \\
\hline Luxemburg & 10.6 & 11.6 & 12.6 & 28.0 & 37.4 & 34.2 & 47.3 \\
\hline Hungary & 68.5 & 62.2 & 68.9 & 6.0 & 18.2 & -3.5 & 18.7 \\
\hline Poland & 340.1 & 286.2 & 325.1 & 6.0 & 18.2 & -11.7 & 14.4 \\
\hline Cyprus & 4.5 & 8.1 & 8.9 & 8.0 & 20.0 & 48.9 & 59.5 \\
\hline Czech Republic & 158.8 & 103.1 & 100.5 & 8.0 & 20.0 & -41.7 & -26.5 \\
\hline Malta & 2.5 & 3.3 & 4.2 & 8.0 & 20.0 & 30.3 & 52.4 \\
\hline Slovakia & 51.4 & 41.6 & 46.2 & 8.0 & 20.0 & -13.7 & 11.0 \\
\hline Slovenia & 10.9 & 14.0 & 15.4 & 8.0 & 20.0 & 28.4 & 43.3 \\
\hline Estonia & 36.6 & 14.2 & 11.8 & 8.0 & 20.0 & -137.1 & -148.3 \\
\hline Latvia & 16.9 & 8.3 & 9.9 & 8.0 & 20.0 & -87.3 & -36.6 \\
\hline Lithuania & 32.2 & 17.2 & 22.0 & 8.0 & 20.0 & -72.2 & -17.1 \\
\hline Bulgaria & 73.6 & 42.9 & 43.0 & 8.0 & 20.0 & -57.8 & -37.0 \\
\hline Romania & 168.6 & 90.3 & 100.6 & 8.0 & 20.0 & -71.8 & -34.1 \\
\hline Canada & 473.0 & 681.0 & 757.0 & 6.0 & 11.0 & 34.7 & 44.4 \\
\hline \begin{tabular}{|l|} 
Japan \\
\end{tabular} & 990.0 & 1211.0 & 1240.0 & 6.0 & 11.0 & 23.2 & 28.9 \\
\hline Russia & 2347.0 & 1732.0 & 1971.0 & 0.0 & 5.0 & -35.5 & -13.1 \\
\hline Australia & 294.0 & 520.0 & 582.0 & -8.0 & -40.0 & 38.9 & 29.3 \\
\hline United States & 4989.0 & 6561.0 & 7461.0 & 7.0 & \begin{tabular}{|l|}
-10.0 \\
\end{tabular} & 29.3 & 26.4 \\
\hline
\end{tabular}

Sources: EU (2003): European Energy and Transport Trends to 2030; US Department of Energy (2005): International Energy Outlook; own calculations 


\subsection{Model regions and sectors}

Table 3: PACE model regions

\begin{tabular}{|c|c|c|}
\hline EU-15 & EU-12 & Non-EU regions \\
\hline Austria & Hungary & Japan \\
\hline Belgium & Poland & Canada \\
\hline Germany & Czech Republic & Russian Federation \\
\hline Denmark & Slovakia & Rest of Former Soviet Union \\
\hline Finland & Bulgaria & Australia \\
\hline France & Romania & New Zealand \\
\hline United Kingdom & \multirow{2}{*}{$\begin{array}{l}\text { Baltic States (Estonia, } \\
\text { Latvia, Lithuania) }\end{array}$} & United States \\
\hline Greece & & China including Hong Kong \\
\hline Ireland & \multirow{2}{*}{$\begin{array}{l}\text { Rest of EU (Slovenia, } \\
\text { Luxembourg, Malta, Cyprus) }\end{array}$} & India \\
\hline Italy & & Rest of East South Asia \\
\hline Netherlands & & Brazil \\
\hline Portugal & & Central and South America \\
\hline Spain & & South Africa \\
\hline Sweden & & Rest of World \\
\hline
\end{tabular}

Table 4: PACE model sectors

\begin{tabular}{|l|l|l|}
\hline \multicolumn{1}{|c|}{ ETS sectors } & \multicolumn{1}{c|}{ Other sectors } \\
\cline { 1 - 1 } Refined oil products & \multirow{4}{*}{$\begin{array}{l}\text { Rectors } \\
\text { Rest of Industry (Other } \\
\text { Electricity }\end{array}$} & Coal \\
\cline { 1 - 1 } $\begin{array}{l}\text { Iron and steel industry } \\
\text { Paper products and } \\
\text { publishing }\end{array}$ & & \\
\cline { 1 - 1 } Non-ferrous metals & & \\
\cline { 1 - 1 } Mineral products & & \\
\hline
\end{tabular}




\subsection{Regional allowance allocation}

Table 5: Allocation factor by region in 2020

\begin{tabular}{|l|c|}
\hline \multicolumn{1}{|c|}{ Region } & Allocation factor \\
\hline Austria & 0.813 \\
\hline Belgium & 0.943 \\
\hline Germany & 0.876 \\
\hline Denmark & 0.752 \\
\hline Spain & 0.693 \\
\hline France & 0.907 \\
\hline Finland & 1.000 \\
\hline Greece & 0.807 \\
\hline Ireland & 0.750 \\
\hline Italy & 0.849 \\
\hline Netherlands & 0.893 \\
\hline Portugal & 0.839 \\
\hline Sweden & 1.000 \\
\hline United Kingdom & 0.900 \\
\hline Czech Republic & 0.825 \\
\hline Estonia & 0.644 \\
\hline Hungary & 0.887 \\
\hline Lithuania & 0.953 \\
\hline Latvia & 0.736 \\
\hline Luxembourg & 0.839 \\
\hline Poland & 0.833 \\
\hline Slovenia & 0.777 \\
\hline Slovakia & 0.929 \\
\hline Cyprus & 0.881 \\
\hline Malta & 0.997 \\
\hline Bulgaria & 1.000 \\
\hline Romania & 1.000 \\
\hline Japan & 0.900 \\
\hline Canada & 0.900 \\
\hline Russian Federation & 1.000 \\
\hline United States & 0.950 \\
\hline Australia & 0.950 \\
\hline & \\
\hline & \\
\hline
\end{tabular}

Source: EU (2007b), own calculations 


\subsection{Competitiveness indicators}

We implement the following indicators into the PACE model in order to account for sectoral and economy-wide competitiveness effects:

- Terms of Trade (ToT):

$$
\operatorname{ToT}_{i}=\frac{P_{X_{i}}}{P_{M_{i}}}
$$

where $P_{X_{i}}$ denotes the price of exports and $P_{M_{i}}$ denotes the price of imports, for a particular region $i$ the ToT index expresses the price of its exports in terms of its imports. The Terms of Trade improve (deteriorate) as the index increases (decreases).

- Revealed Comparative Advantage (RCA)

For a particular region and sector, this index compares the ratio of exports by a specific sector over its imports with the ratio of exports over imports across all sectors of the region. Letting $X$ denote exports, $M$ imports, $i$ the region and $j$ the sector, the index for revealed comparative advantage (RCA) for region $i$ in sector $j$ can be presented as follows:

$$
R C A_{i j}=\frac{X_{i j} / M_{i j}}{\sum_{j} X_{i j} / \sum_{j} M_{i j}}
$$

If the sectoral export-import ratio is identical to the economy-wide ratio, the RCA index takes the neutral value of one $\left(R C A_{i j}=1\right)$. Thus, a region $i$ is said to have a revealed comparative advantage in sector $j$ if the RCA index exceeds unity $(1<R C A \leq \infty)$. By contrast, a region $i$ has a revealed comparative disadvantage in sector $j$ if the RCA index takes the values between zero and one $(0 \leq R C A<1)$.

- Relative World Trade Shares (RWS)

This index compares the ratio of country's exports in a certain sector over the world's exports in this sector with the ratio of country's overall exports over the world's exports in all sectors:

$$
R W S_{i j}=\frac{X_{i j} / \sum_{i} X_{i j}}{\sum_{j} X_{i j} / \sum_{i} \sum_{j} X_{i j}} .
$$

The RWS indicator lies in the same value range as the RCA indicator $\left(0 \leq R W S_{i j} \leq \infty\right)$ and may thus be interpreted analogously. 


\subsection{Numerical simulation results}

Table 6: Core allowance allocation - Environmental and macroeconomic indicators in 2020

\begin{tabular}{|c|c|c|c|c|c|c|c|c|}
\hline Region & $\boldsymbol{E} \boldsymbol{U}$ & $\boldsymbol{E} \boldsymbol{U}^{+}$ & $\boldsymbol{E} \boldsymbol{U}^{++}$ & $\boldsymbol{E U}^{+++}$ & $E U_{-} C D M$ & $E U^{+} \_C D M$ & $E U^{++}{ }_{-} C D M$ & $E U_{-}^{+++} C D M$ \\
\hline & \multicolumn{8}{|c|}{ Carbon emissions reduction (in \% vs. BaU) } \\
\hline$E U-27$ & -27.30 & -25.70 & -23.00 & -20.50 & -16.70 & -17.00 & -16.80 & -17.50 \\
\hline Canada & -36.40 & -38.70 & -36.50 & -34.90 & -36.40 & -33.30 & -33.20 & -33.50 \\
\hline Japan & -23.60 & -28.70 & -26.70 & -24.60 & -23.60 & -21.90 & -21.80 & -22.40 \\
\hline Russia & 2.80 & 2.50 & -8.10 & -5.30 & 2.50 & 2.30 & -2.00 & -2.60 \\
\hline Australia & -21.90 & -21.90 & -21.90 & -22.70 & -21.90 & -21.90 & -21.90 & -17.40 \\
\hline \multirow[t]{2}{*}{ United States } & -14.10 & -14.10 & -14.10 & -16.80 & -14.10 & -14.10 & -14.10 & -13.90 \\
\hline & \multicolumn{8}{|c|}{$\mathrm{CO} 2$ value in ETS sectors (in \$US per ton of $\mathrm{CO}_{2}$ ) } \\
\hline$E U-27$ & 26.36 & 21.17 & 14.27 & 8.24 & 4.32 & 4.27 & 4.23 & 3.87 \\
\hline Canada & 104.31 & 21.17 & 14.27 & 8.24 & 103.90 & 4.27 & 4.23 & 3.87 \\
\hline Japan & 94.90 & 21.17 & 14.27 & 8.24 & 94.96 & 4.27 & 4.23 & 3.87 \\
\hline Russia & 0.00 & 0.00 & 14.27 & 8.24 & 0.00 & 0.00 & 4.23 & 3.87 \\
\hline Australia & 23.40 & 22.94 & 23.03 & 8.24 & 23.24 & 22.66 & 22.77 & 3.87 \\
\hline \multirow[t]{2}{*}{ United States } & 20.10 & 19.77 & 19.79 & 8.24 & 19.90 & 19.55 & 19.62 & 3.87 \\
\hline & \multicolumn{8}{|c|}{ Production impact (in \% vs. BaU) } \\
\hline$E U-27$ & -3.46 & -3.5 & -3.49 & -3.36 & -3.48 & -3.45 & -3.46 & -3.44 \\
\hline Canada & -0.48 & -2.49 & -2.52 & -2.47 & -0.45 & -2.56 & -2.57 & -2.46 \\
\hline Japan & -0.35 & -1.25 & -1.24 & -1.22 & -0.34 & -1.22 & -1.22 & -1.21 \\
\hline Russia & 1.04 & 1.10 & 0.75 & 1.04 & 1.09 & 1.14 & 1.02 & 1.16 \\
\hline Australia & 0.38 & 0.41 & 0.41 & -2.76 & 0.37 & 0.41 & 0.41 & -2.8 \\
\hline \multirow[t]{3}{*}{ United States } & -0.09 & -0.06 & -0.06 & -0.28 & -0.09 & -0.05 & -0.05 & -0.26 \\
\hline & & & & & & & & \\
\hline & \multicolumn{8}{|c|}{ Welfare impact (in \% of HEV) } \\
\hline$E U-27$ & -2.98 & -2.98 & -2.98 & -2.96 & -2.95 & -2.95 & -2.95 & -2.95 \\
\hline Canada & -0.91 & -2.14 & -2.16 & -2.18 & -0.92 & -2.17 & -2.17 & -2.20 \\
\hline Japan & -0.03 & -0.51 & -0.52 & -0.52 & -0.03 & -0.53 & -0.53 & -0.53 \\
\hline Russia & -1.82 & -1.93 & -1.53 & -1.98 & -1.83 & -1.94 & -1.87 & -2.12 \\
\hline Australia & -0.46 & -0.45 & -0.45 & -3.08 & -0.45 & -0.43 & -0.44 & -3.07 \\
\hline United States & 0.10 & 0.02 & 0.02 & 0.05 & 0.01 & 0.02 & 0.02 & -0.05 \\
\hline
\end{tabular}


Table 7: Core allowance allocation - Economy-wide and sectoral competitiveness indicators in 2020

\begin{tabular}{|c|c|c|c|c|c|c|c|c|c|c|c|c|c|c|c|c|}
\hline Region & \multicolumn{2}{|c|}{$\boldsymbol{E U}$} & \multicolumn{2}{|c|}{$\boldsymbol{E} \boldsymbol{U}^{+}$} & \multicolumn{2}{|c|}{$\boldsymbol{E} \boldsymbol{U}^{++}$} & \multicolumn{2}{|c|}{$\boldsymbol{E} \boldsymbol{U}^{+++}$} & \multicolumn{2}{|c|}{$E U_{-} C D M$} & \multicolumn{2}{|c|}{$E U_{-}^{+} C D M$} & \multicolumn{2}{|c|}{$E U_{-}^{++} C D M$} & \multicolumn{2}{|c|}{$E U^{+++} \_C D M$} \\
\hline & \multicolumn{16}{|c|}{ Terms of Trade impact (in \% vs. BaU) } \\
\hline$E \boldsymbol{U}-27$ & & -3.10 & & -3.30 & & -3.30 & & -2.90 & & -3.20 & & -3.20 & & -3.20 & & -3.20 \\
\hline Canada & & 0.90 & & 2.10 & & 2.30 & & 2.40 & & 0.90 & & 2.40 & & 2.40 & & 2.50 \\
\hline Japan & & -2.30 & & -4.50 & & -4.30 & & -4.20 & & -2.30 & & -4.10 & & -4.10 & & -4.10 \\
\hline Russia & & 11.00 & & 11.20 & & 5.60 & & 9.30 & & 10.80 & & 11.0 & & 9.50 & & 10.90 \\
\hline Australia & & 2.40 & & 2.20 & & 2.30 & & 1.90 & & 2.20 & & 1.90 & & 2.10 & & 2.10 \\
\hline \multirow[t]{3}{*}{ United States } & & -0.90 & & -0.30 & & -0.30 & & -2.30 & & -0.20 & & -0.40 & & -0.30 & & -1.40 \\
\hline & \multicolumn{16}{|c|}{ Revealed Comparative Advantage - RCA (in \% vs. BaU) } \\
\hline & ETS & NETS & ETS & NETS & ETS & NETS & ETS & NETS & ETS & NETS & ETS & NETS & ETS & NETS & ETS & NETS \\
\hline$E \boldsymbol{U}-27$ & 10.32 & -1.16 & 9.99 & -1.12 & 11.33 & -1.26 & 10.70 & -1.19 & 13.66 & -1.50 & 12.19 & -1.35 & 12.39 & -1.37 & 11.38 & -1.26 \\
\hline Canada & -22.02 & 3.63 & 9.92 & -1.15 & 12.93 & -1.55 & 12.27 & -1.41 & -22.68 & 3.75 & 16.11 & -1.94 & 16.31 & -1.97 & 12.83 & -1.46 \\
\hline Japan & -11.73 & 1.02 & 9.10 & -0.56 & 11.09 & -0.70 & 9.81 & -0.61 & -12.04 & 1.05 & 12.19 & -0.77 & 12.55 & -0.80 & 10.14 & -0.63 \\
\hline Russia & -4.58 & 1.82 & -6.72 & 2.84 & -23.1 & 9.88 & -18.49 & 7.81 & -6.37 & 2.45 & -8.31 & 3.46 & -13.49 & 5.59 & -14.26 & 5.98 \\
\hline Australia & -23.88 & 5.51 & -25.75 & 5.99 & -25.54 & 5.93 & 9.13 & -0.47 & -24.26 & 5.61 & -26.26 & 6.13 & -26.1 & 6.08 & 15.47 & -1.64 \\
\hline \multirow[t]{3}{*}{ United States } & -4.98 & 0.39 & -11.04 & 0.93 & -11.33 & 0.96 & -7.13 & 0.53 & -5.88 & 0.47 & -12.44 & 1.06 & -12.33 & 1.05 & -6.54 & 0.47 \\
\hline & \multicolumn{16}{|c|}{ Relative World Trade Shares - RWS (in \% vs. BaU) } \\
\hline & ETS & NETS & ETS & NETS & ETS & NETS & ETS & NETS & ETS & NETS & ETS & NETS & ETS & NETS & ETS & NETS \\
\hline EU-27 & 4.13 & -0.34 & 3.19 & -0.32 & 4.04 & -0.41 & 3.25 & -0.38 & 5.08 & -0.51 & 3.49 & -0.42 & 3.72 & -0.44 & 3.08 & -0.41 \\
\hline Canada & 28.68 & 2.20 & 52.54 & -0.78 & 55.34 & -1.10 & 53.99 & -0.99 & 27.71 & 2.25 & 56.72 & -1.37 & 57.06 & -1.40 & 53.59 & -1.01 \\
\hline Japan & 37.21 & 0.43 & 45.43 & -0.13 & 47.06 & -0.22 & 46.00 & -0.23 & 36.56 & 0.43 & 46.94 & -0.27 & 47.31 & -0.29 & 45.74 & -0.25 \\
\hline Russia & 45.95 & 1.26 & 43.43 & 2.12 & 31.23 & 7.76 & 34.92 & 6.07 & 44.51 & 1.72 & 41.87 & 2.60 & 38.18 & 4.33 & 37.68 & 4.60 \\
\hline Australia & 23.46 & 4.24 & 20.69 & 4.60 & 21.30 & 4.52 & 45.45 & 0.24 & 22.70 & 4.30 & 19.61 & 4.70 & 19.96 & 4.66 & 50.82 & -0.80 \\
\hline United States & 43.51 & 0.01 & 38.15 & 0.20 & 38.12 & 0.20 & 38.39 & 0.12 & 42.42 & 0.02 & 36.62 & 0.23 & 36.80 & 0.23 & 38.11 & 0.10 \\
\hline
\end{tabular}


Table 8: Proportional allowance allocation - Environmental and macroeconomic indicators in 2020

\begin{tabular}{|c|c|c|c|c|c|c|c|c|}
\hline Region & $\boldsymbol{E} \boldsymbol{U}$ & $\boldsymbol{E} \boldsymbol{U}^{+}$ & $\boldsymbol{E} \boldsymbol{U}^{++}$ & $E \boldsymbol{U}^{+++}$ & $E U_{-} C D M$ & $E U_{-}^{+} C D M$ & $E U^{++} \_C D M$ & $E U^{+++} C D M$ \\
\hline & \multicolumn{8}{|c|}{ Carbon emissions reduction (in \% vs. BaU) } \\
\hline$E \boldsymbol{E}-27$ & -26.50 & -26.90 & -23.60 & -21.90 & -15.60 & -16.00 & -15.90 & -16.60 \\
\hline Canada & -36.40 & -33.00 & -29.90 & -28.50 & -36.40 & -24.30 & -24.30 & -24.70 \\
\hline Japan & -23.60 & -23.80 & -21.00 & -19.50 & -23.60 & -14.20 & -14.10 & -14.90 \\
\hline Russia & 3.00 & 2.90 & -10.20 & -8.30 & 2.70 & 2.50 & -2.00 & -2.80 \\
\hline Australia & -21.90 & -21.90 & -21.90 & -22.00 & -21.90 & -21.90 & -21.90 & -12.40 \\
\hline \multirow[t]{2}{*}{ United States } & -14.10 & -14.10 & -14.10 & -16.00 & -14.10 & -14.10 & -14.10 & -10.30 \\
\hline & \multicolumn{8}{|c|}{ CO2 value in ETS sectors (in \$US per ton of $\mathrm{CO}_{2}$ ) } \\
\hline$E U-27$ & 31.73 & 33.68 & 20.54 & 15.27 & 4.45 & 4.66 & 4.61 & 4.85 \\
\hline Canada & 105.03 & 33.68 & 20.54 & 15.27 & 104.55 & 4.66 & 4.61 & 4.85 \\
\hline Japan & 93.46 & 33.68 & 20.54 & 15.27 & 93.38 & 4.66 & 4.61 & 4.85 \\
\hline Russia & 0 & 0 & 20.54 & 15.27 & 0 & 0 & 4.61 & 4.85 \\
\hline Australia & 23.70 & 23.48 & 23.57 & 15.27 & 23.51 & 23.04 & 23.14 & 4.85 \\
\hline \multirow[t]{2}{*}{ United States } & 19.85 & 19.72 & 19.72 & 15.27 & 19.72 & 19.37 & 19.44 & 4.85 \\
\hline & \multicolumn{8}{|c|}{ Production impact (in \% vs. BaU) } \\
\hline$E \boldsymbol{U}-27$ & -1.73 & -1.72 & -1.70 & -1.67 & -1.66 & -1.65 & -1.65 & -1.65 \\
\hline Canada & -1.73 & -1.72 & -1.70 & -1.67 & -1.66 & -1.65 & -1.65 & -1.65 \\
\hline Japan & -0.58 & -1.14 & -1.20 & -1.19 & -0.55 & -1.25 & -1.25 & -1.17 \\
\hline Russia & -0.37 & -0.62 & -0.59 & -0.58 & -0.37 & -0.55 & -0.55 & -0.55 \\
\hline Australia & 0.82 & 0.84 & 0.38 & 0.56 & 0.86 & 0.88 & 0.76 & 0.81 \\
\hline \multirow[t]{3}{*}{ United States } & 0.30 & 0.32 & 0.32 & -0.15 & 0.30 & 0.32 & 0.32 & -0.26 \\
\hline & -0.12 & -0.11 & -0.10 & -0.18 & -0.12 & -0.09 & -0.09 & -0.14 \\
\hline & \multicolumn{8}{|c|}{ Welfare impact (in \% of HEV) } \\
\hline$E U-27$ & -0.85 & -0.84 & -0.84 & -0.84 & -0.81 & -0.81 & -0.81 & -0.81 \\
\hline Canada & -0.89 & -1.02 & -1.00 & -0.99 & -0.89 & -0.92 & -0.92 & -0.94 \\
\hline Japan & -0.04 & -0.13 & -0.13 & -0.12 & -0.04 & -0.12 & -0.12 & -0.12 \\
\hline Russia & -1.45 & -1.51 & -0.84 & -1.17 & -1.45 & -1.50 & -1.43 & -1.54 \\
\hline Australia & -0.45 & -0.45 & -0.45 & -0.58 & -0.44 & -0.42 & -0.43 & -0.51 \\
\hline United States & -0.01 & 0 & 0 & 0 & 0 & 0.01 & 0.01 & 0.01 \\
\hline
\end{tabular}


Table 9: Proportional allowance allocation - Economy-wide and sectoral competitiveness indicators in 2020

\begin{tabular}{|c|c|c|c|c|c|c|c|c|c|c|c|c|c|c|c|c|}
\hline \multirow{2}{*}{ Region } & \multicolumn{2}{|c|}{$E \boldsymbol{U}$} & \multicolumn{2}{|c|}{$\boldsymbol{E} \boldsymbol{U}^{+}$} & \multicolumn{2}{|c|}{$\boldsymbol{E} \boldsymbol{U}^{++}$} & \multicolumn{2}{|c|}{$\boldsymbol{E} \boldsymbol{U}^{+++}$} & \multicolumn{2}{|c|}{$E U \_C D M$} & \multicolumn{2}{|c|}{$E U_{-}^{+} C D M$} & \multicolumn{2}{|c|}{$E U^{++} \_C D M$} & \multicolumn{2}{|c|}{$E U_{-}^{+++} C D M$} \\
\hline & \multicolumn{16}{|c|}{ Terms of Trade impact (in \% vs. BaU) } \\
\hline$E U-27$ & & -2.80 & & -2.80 & & -2.60 & & -2.60 & & -2.50 & & -2.60 & & -2.60 & & -2.60 \\
\hline Canada & & 0.80 & & 1.50 & & 1.70 & & 1.80 & & 0.80 & & 1.70 & & 1.70 & & 1.80 \\
\hline Japan & & -2.30 & & -3.10 & & -2.90 & & -2.90 & & -2.30 & & -2.70 & & -2.70 & & -2.70 \\
\hline Russia & & 10.10 & & 10.30 & & 2.20 & & 4.80 & & 9.70 & & 9.60 & & 8.00 & & 8.40 \\
\hline Australia & & 2.20 & & 2.20 & & 2.30 & & 1.80 & & 2.10 & & 1.80 & & 1.90 & & 1.90 \\
\hline \multirow[t]{3}{*}{ United States } & & -0.30 & & -0.30 & & -0.30 & & -1.00 & & -0.30 & & -0.40 & & -0.40 & & -0.60 \\
\hline & \multicolumn{16}{|c|}{ Revealed Comparative Advantage - RCA (in \% vs. BaU) } \\
\hline & ETS & NETS & ETS & NETS & ETS & NETS & ETS & NETS & ETS & NETS & ETS & NETS & ETS & NETS & ETS & NETS \\
\hline$E \boldsymbol{U}-27$ & 3.72 & -0.43 & 2.86 & -0.33 & 4.96 & -0.57 & 5.10 & -0.58 & 7.33 & -0.83 & 6.28 & -0.71 & 6.49 & -0.73 & 5.89 & -0.67 \\
\hline Canada & -19.53 & 3.17 & -1.95 & 0.35 & 2.66 & -0.33 & 3.38 & -0.41 & -20.26 & 3.30 & 7.67 & -1.00 & 7.87 & -1.03 & 5.21 & -0.63 \\
\hline Japan & -8.60 & 0.74 & 2.21 & -0.12 & 4.94 & -0.33 & 4.64 & -0.30 & -9.11 & 0.79 & 6.29 & -0.42 & 6.64 & -0.45 & 5.23 & -0.34 \\
\hline Russia & 0.66 & -0.48 & -0.18 & -0.06 & -23.58 & 9.69 & -19.60 & 7.88 & -1.74 & 0.38 & -3.21 & 1.13 & -8.97 & 3.37 & -9.95 & 3.84 \\
\hline Australia & -21.74 & 5.03 & -22.7 & 5.27 & -22.56 & 5.22 & -13.09 & 3.22 & -22.27 & 5.16 & -23.75 & 5.54 & -23.57 & 5.49 & -1.45 & 0.68 \\
\hline \multirow[t]{3}{*}{ United States } & -1.57 & 0.12 & -4.88 & 0.40 & -5.64 & 0.46 & -4.64 & 0.36 & -2.62 & 0.20 & -7.62 & 0.64 & -7.50 & 0.63 & -2.85 & 0.20 \\
\hline & \multicolumn{16}{|c|}{ Relative World Trade Shares - RWS (in \% vs. BaU) } \\
\hline & ETS & NETS & ETS & NETS & ETS & NETS & ETS & NETS & ETS & NETS & ETS & NETS & ETS & NETS & ETS & NETS \\
\hline$E U-27$ & 0.63 & 0.16 & -0.25 & 0.22 & 1.07 & 0.07 & 0.84 & 0.06 & 1.81 & -0.05 & 0.51 & 0.04 & 0.76 & 0.02 & 0.25 & 0.04 \\
\hline Canada & 32.35 & 1.87 & 47.05 & 0.05 & 51.35 & -0.45 & 51.49 & -0.50 & 31.19 & 1.93 & 53.87 & -0.90 & 54.22 & -0.93 & 51.31 & -0.62 \\
\hline Japan & 40.97 & 0.27 & 46.30 & -0.08 & 48.61 & -0.22 & 48.15 & -0.22 & 39.96 & 0.27 & 48.28 & -0.28 & 48.69 & -0.29 & 47.59 & -0.27 \\
\hline Russia & 51.40 & -0.77 & 50.14 & -0.38 & 33.01 & 7.44 & 36.03 & 6.01 & 49.35 & -0.09 & 47.12 & 0.59 & 43.18 & 2.43 & 42.27 & 2.79 \\
\hline Australia & 26.09 & 3.93 & 24.55 & 4.13 & 25.14 & 4.05 & 32.83 & 2.67 & 25.05 & 4.01 & 22.55 & 4.33 & 22.93 & 4.28 & 44.16 & 0.52 \\
\hline United States & 47.88 & -0.16 & 45.06 & -0.05 & 44.64 & -0.04 & 44.15 & -0.04 & 46.47 & -0.14 & 42.15 & 0.02 & 42.34 & 0.02 & 43.89 & -0.10 \\
\hline
\end{tabular}

